NBER WORKING PAPER SERIES

\title{
THE EFFECTS OF ENTRY ON INCUMBENT INNOVATION AND PRODUCTIVITY
}

\author{
Philippe Aghion \\ Richard Blundell \\ Rachel Griffith \\ Peter Howitt \\ Susanne Prantl \\ Working Paper 12027 \\ http://www.nber.org/papers/w12027 \\ NATIONAL BUREAU OF ECONOMIC RESEARCH \\ 1050 Massachusetts Avenue \\ Cambridge, MA 02138 \\ February 2006
}

We are grateful to Fiona Scott-Morton, Francis Kramarz, Stephen Redding, Helen Simpson and seminar participants at Brown University, IFS, Stanford GSB, Yale University and NBER, the Zvi Griliches conference in Paris, the EEA conference and ES World Congress for useful comments and suggestions. This work contains statistical data from the ONS which is Crown Copyright and reproduced with the permission of the controller of HMSO and Queen 's Printer for Scotland (under license number C02W002702). The use of the ONS statistical data in this work does not imply the endorsement of the ONS in relation to the interpretation or analysis of the statistical data. The views expressed herein are those of the author(s) and do not necessarily reflect the views of the National Bureau of Economic Research.

(O2006 by Philippe Aghion, Richard Blundell, Rachel Griffith, Peter Howitt and Susanne Prantl. All rights reserved. Short sections of text, not to exceed two paragraphs, may be quoted without explicit permission provided that full credit, including $\odot$ notice, is given to the source. 
The Effects of Entry on Incumbent Innovation and Productivity

Philippe Aghion, Richard Blundell, Rachel Griffith, Peter Howitt and Susanne Prantl

NBER Working Paper No. 12027

February 2006

JEL No. E2

\begin{abstract}
How does firm entry affect innovation incentives and productivity growth in incumbent firms? Micro-data suggests that there is heterogeneity across industries--incumbents in technologically advanced industries react positively to foreign firm entry, but not in laggard industries. To explain this pattern, we introduce entry into a Schumpeterian growth model with multiple sectors which differ by their distance to the technological frontier. We show that technologically advanced entry threat spurs innovation incentives in sectors close to the technological frontier--successful innovation allows incumbents to prevent entry. In laggard sectors it discourages innovation--increased entry threat reduces incumbents' expected rents from innovating. We find that the empirical patterns hold using rich micro-level productivity growth and patent panel data for the UK, and controlling for the endogeneity of entry by exploiting the large number of policy reforms undertaken during the Thatcher era.

Philippe Aghion

Department of Economics

Harvard University

Cambridge, MA 02138

and NBER

p_aghion@harvard.edu

Richard Blundell

University College London

r.blundell@ucl.ac.uk

Rachel Griffith

University College London

r.griffith@ucl.ac.uk

Peter Howitt

Department of Economics

Brown University, Box B

Providence, RI 02912

and NBER

peter_howitt@brown.edu

Susanne Prantl

WZB

Humboldt University

prantl@wz-berlin.de
\end{abstract}




\section{Introduction}

There is a long standing interest in the effects of firm entry, which are widely recognized as major drivers of economic growth. Entry can induce reallocation of inputs and outputs, trigger knowledge spillovers and affect innovation incentives in incumbent firms. Entry by foreign firms has been a focus of attention in recent years, particularly in countries or industries behind the technological frontier, and has spurred widespread policy reforms aimed at fostering the free movement of goods, services, capital and firm management. Empirical studies on the effects of market liberalizations and foreign direct investment provide, however, mixed results on incumbent reactions. ${ }^{1}$ In this paper we take a new look at this issue. We combine theoretical and empirical analysis to investigate a major source of systematic heterogeneity in foreign firm entry effects on incumbent innovation incentives and productivity growth across industries, time and economic environments.

We are motivated by the following empirical regularity - we see substantial heterogeneity in the effects of foreign firm entry on average incumbent total factor productivity (TFP) growth when we look across industries in the United Kingdom (UK). In some industries entry has a strongly positive effect, while in others it seems to depress incumbent TFP growth. Positive effects are found in technologically advanced industries, and weak or even negative ones in technologically laggard industries. This is illustrated in Figure 1, where we plot the foreign entry rate in an industry at time $t-1$ against the average TFP growth estimate for incumbent establishments in that industry at time $t$. The sample is split at the median distance to the technological frontier, as measured on the industry level by relative US-UK labor productivity. ${ }^{2}$

[Figure 1 here]

This finding of heterogeneous entry effects is compelling, but we find no ready explanation

\footnotetext{
${ }^{1}$ See, inter alia, Aitken and Harrison (1999), Pavcnik (2002) and Javorcik (2004) and the literature cited there.

${ }^{2}$ See notes below figure 1 and section 4 for a description of the data and variables used here.
} 
in the theoretical literature. Our contribution in this paper is first to discuss in detail a theoretical explanation that is consistent with this form of heterogeneity, then to explore the robustness of the finding using micro panel data, and paying particular attention to the problem of entry endogeneity in incumbent performance equations.

Our theoretical explanation comes from a multi-sector Schumpeterian growth model with entry threat that affects the innovative effort by incumbent firms in a systematically different way according to the initial state of technological development in the industry. We focus on technologically advanced entry in the theoretical part of the paper, which accords well with our foreign firm entry measure in Figure 1, since firms that operate internationally are more likely to produce at the technological frontier. ${ }^{3}$ A main implication of the model is that higher threat of technologically advanced entry should encourage innovation by incumbents in sectors that are initially close to the technological frontier. This escape-entry effect is similar to the escape-competition effect analyzed in Aghion et al. (2001, 2005a). Incumbents that are further behind the frontier have no hope to win against a potential entrant, and therefore the effect of an increased entry threat is to reduce the incumbents' expected payoff from investing in R\&D. This discouragement effect is similar to the Schumpeterian appropriability effect of product market competition. The effects of entry on incumbent productivity growth in sectors near and further behind the technological frontier mirror the heterogeneous pattern of entry effects on innovation incentives.

The descriptive evidence provided in Figure 1 is of course not sufficient to establish a causal relationship from entry to incumbent performance, measured by innovative activity or productivity growth. The entry threat variable used in the theoretical model is not observable, and it is endogenous in incumbent performance equations, as we show in greater detail in the paper. Using, as we do, actual entry as a proxy for entry threat, only worsens the endogeneity problem. ${ }^{4}$ To deal with this we exploit as instruments the large number of

\footnotetext{
${ }^{3}$ See section 4.2 for details.

${ }^{4}$ The reason is that actual entry deviates from entry threat only in situations where entrants may lose against incumbents and the difference between entry threat and actual entry then depends again on incumbent performance in form of innovative activity.
} 
policy interventions that substantially changed the conditions for foreign entry in the UK during the 1980s and 1990s in different industries at different times. The instruments we use are shown to have a strong influence on foreign entry, conditional on other covariates in the model such as competition and trade. To measure actual entry of foreign firms and separate it out from domestic firm entry for a large number of 4-digit manufacturing industries we can use rich panel data on the population of manufacturing plants and their ownership. We link US and UK data to identify industries that are near or further away from the technological frontier and control for endogeneity of the distance to frontier using US technology and production information as additional instruments. We complement our productivity growth analysis by investigating entry effects on incumbent firms' patenting behavior, which is a more direct measure of innovative efforts. Also, we consider the effects of domestic entry on incumbent performance, and relate these to our theoretical analysis. Finally, we argue why the two most likely alternative explanations based on knowledge spillovers do not explain the full pattern of our empirical findings.

Our theoretical analysis relates to several papers in the theoretical IO literature, in particular Gilbert and Newbery (1982) on preemption, and Laffont and Tirole (1993) on the regulation of entry. Laffont and Tirole analyze the welfare effects of entry regulation in a model of product differentiation. However, they do not allow for incumbent innovation, and concentrate instead on how entry regulation affects the size of innovations, or the extent of differentiation, by newly entering firms. Fudenberg and Tirole (1984) and Tirole (1988) analyze the strategic interaction between entrants and incumbents. Barro and Sala-i-Martin (2004) and Aghion et al. (2005a) focus on competition among incumbent firms and its effects on growth, but they do not consider entry. Recent theory papers focussing on reallocative effects of entry and trade liberalization reforms are Melitz (2003) and Bernard et al. (2003). In contrast, this paper focuses on the way in which entry effects growth through within-firm innovation effects in incumbents.

Our empirical analysis relates to several different strands of empirical work. First, there 
is the empirical literature on the effects of trade liberalization and foreign direct investment. Studies including Aitken and Harrison (1999), Pavcnik (2002), and Javorcik (2004) are, as ours, based on plant or firm data and exploit variation of trade and entry across industries and time. ${ }^{5}$ Second, there is an empirical IO literature, following the work of Bresnahan and Reiss $(1990,1991)$ and Berry $(1992) .{ }^{6}$ The emphasis in these papers is on entry in well defined, oligopolistic markets and on endogeneity of market structure. Olley and Pakes (1996) investigate the effects of deregulation on aggregate productivity growth and the underlying reallocation mechanism in one particular industry. We focus instead on the heterogeneity in entry effects on incumbent innovation and productivity growth across markets. Another related strand is the literature on product market competition, firm performance and innovation, in particular Nickell (1996), Blundell et al. (1999), and Aghion et al. (2005a).

More directly linked to this paper, Aghion et. al. (2004) analyze entry effects on average incumbent productivity growth and show that industries with higher changes of the employment share in foreign firms experience, on average, higher growth of total factor productivity in incumbents. Aghion and Griffith (2005) provide a summary of recent theoretical and empirical literature on competition, entry and growth.

Our result that entry threat has positive effects on incumbent innovation incentives and productivity growth in industries initially close to the technological frontier, but not in those industries that are initially further behind the frontier, has direct implications for the policy debate on market (de)regulation, competition policy, large scale privatization, and trade liberalization. This debate underlies the consideration of costs and benefits of globalization and the discussion on entry regulation in different countries and industries. ${ }^{7}$ What our analysis suggests is that policies aiming at decreasing or removing entry barriers alone may

\footnotetext{
${ }^{5}$ Plant or firm level data is also used by Bertschek (1995), Griffith et al. (2002), Haskel et al. (2002), Keller and Yeaple (2004). Aghion et al. (2005b) rely on industry level panel data to analyze the unequalizing effects of delicensing reforms on manufacturing industry performance across states in India.

${ }^{6}$ Recent examples are, among others, Mazzeo (2002) and Seim (2004). Berry and Pakes (2003) provide an excellent overview.

${ }^{7}$ Djankov et al. (2002), for example, present comparative data on direct entry regulation in 85 countries. Bertrand and Kramarz (2002) look at employment effects of entry regulation in the French retail industry. See also Nicoletti and Scarpetta (2004).
} 
not be sufficient to foster productivity growth of incumbent firms in all industries, even when such policies can be shown to be growth-enhancing on average. This, in turn, may suggest complementary policies to facilitate the reallocation of factors and resources from less to more technologically developed industries that react more positively to entry threat. Regulation that inhibits such reallocation should be reduced.

The paper is organized as follows. In section 2 we sketch the key elements of the theoretical model; further theoretical analysis is provided in section 5.3 and Appendix A. We specify the empirical models in section 3 and describe data and variable construction in section 4 . Empirical results are presented in section 5 and in section 6 we conclude.

\section{A theoretical explanation for heterogeneity in entry effects}

To explain the heterogeneous entry effects illustrated in Figure 1 we introduce technologically advanced entry into a multi-sector Schumpeterian growth model. ${ }^{8}$ The model implies that higher entry threat has a positive effect on economic performance of incumbent firms in sectors that are initially close to the technological frontier, whereas it may damage the performance of firms in sectors that are initially further behind the frontier.

\subsection{Basic model}

In each period $t$ a final good, henceforth the numéraire, is produced under perfect competition using a continuum of intermediate inputs, according to the technology:

$$
y_{t}=\int_{0}^{1} A_{t}(i)^{1-\alpha} x_{t}(i)^{\alpha} d i, \alpha \in(0,1)
$$

where $x_{t}(i)$ denotes the quantity of the intermediate input produced in sector $i$ and $A_{t}(i)$ is the productivity parameter associated with the latest version of that input.

For each intermediate product there are two firms capable of producing an innovation. Intermediate producers live for only one period, and property rights over their technological

\footnotetext{
${ }^{8}$ A simplified version of this model with a fixed probability $p$ of entry is sketched in Aghion et al. (2004) and in Aghion and Griffith (2005).
} 
capabilities are transmitted within dynasties. The final good is used as capital in the production of intermediate goods with a one-for-one technology. We assume Bertrand competition within each intermediate sector.

In any sector where both firms have access to the same technology, Bertrand competition implies zero profits. In any sector where one firm (the "leader") has a better technology than the other (the "laggard"), only the leader will actively produce. As shown in Zilibotti et al. (2005), the equilibrium profit for each leader takes the form:

$$
\pi_{t}(i)=\delta A_{t}(i), \quad \delta=(1-\alpha) \alpha^{\frac{1+\alpha}{1-\alpha}}
$$

\subsection{Technological states, innovation, and entry}

The world's "technological frontier" at the end of each period $t$ is characterized by a technology parameter $\bar{A}_{t}$ which grows at the exogenous rate $\gamma-1>0$ :

$$
\bar{A}_{t}=\gamma \bar{A}_{t-1}
$$

At the beginning of period $t$ intermediate firms can be of three types. Firms of type 1 operate at the current frontier, with a productivity level $A_{t-1}(i)=\bar{A}_{t-1}$. Type-2 firms are one step behind the frontier, with $A_{t-1}(i)=\bar{A}_{t-2}$, and type-3 firms are two steps behind, with $A_{t-1}(i)=\bar{A}_{t-3}$.

Innovation allows an incumbent firm to increase its productivity by the factor $\gamma$ and thereby to keep up with growth of the frontier. ${ }^{9}$ The cost of technology adoption is quadratic in its hazard rate and also proportional to the targeted level of productivity. More specifically, by incurring a cost

$$
c_{j t}=c \cdot\left(z^{2} / 2\right) \bar{A}_{t-j}, c>0,
$$

\footnotetext{
${ }^{9}$ The assumption of "step-by-step" technological progress is made here for the sake of tractability. As in Aghion et al. (2001), this assumption avoids having to deal with asymmetries in the decision problems of firms at different distances from the technological frontier. If we allowed innovating type-2 firms to catch up with the frontier with sufficiently high probability the discouragement effect of entry on type- 2 firms would turn into an escape-entry effect. In that case, our model would predict higher rates of innovation and productivity growth for type- 2 firms than for type- 1 firms, a prediction which is not borne by our data and empirical analysis.
} 
at the beginning of period $t$, a type- $j$ incumbent, where $j \in\{1,2\}$, can increase its productivity with probability $z$ by the factor $\gamma$ within that period, adopting the next most productive technology. With probability $1-z$ the incumbent's productivity does not increase, and lags by $j+1$ steps behind the new frontier. The most backward (type-3) firms are automatically upgraded by the factor $\gamma$ as in Aghion et al. (1997). This reflects the idea that the cost of technological adoption becomes negligible for sufficiently mature technologies.

In each period and intermediate sector, there is one outside producer that can pay for an entry opportunity. We focus on technologically advanced entry; thus when entry occurs it takes place at the new frontier $\bar{A}_{t} \cdot{ }^{10}$ An entrant will steal all the market and become the new leading firm unless the incumbent leader also has the frontier technology $\bar{A}_{t}$ after the innovation process described above, in which case we assume that the incumbent retains the entire market. ${ }^{11}$

Note that incumbent laggards will never invest in innovation, because an innovation would at best allow the firm to catch up to its rival and would still leave the firm with zero profits. Note also that in steady state there are no intermediate sectors in which the incumbents are both type-1 or both type-2. This is because such a ("level") sector would have to have been level in the previous period, since non-innovating laggards never catch up to their leader, whereas innovation and entry will eventually unlevel the sector.

Thus, in the long run, all intermediate sectors will be in one of only three possible "states" at the beginning of any period: (a) state- 1 sectors are those with a type-1 leader; (b) state2 sectors are those with a type-2 leader and (c) state- 3 sectors are those with two type-3

\footnotetext{
${ }^{10}$ More generally, one can think of several potential entrants with heterogeneous and a priori uncertain productivities, who are racing for entry into a particular industry. As long as at least one potential entrant has a high productivity realization $\bar{A}_{t}$, the analysis and comparative static results will remain the same as if we assume only one potential entrant with productivity $\bar{A}_{t}$. See section 5.3 .2 for a discussion of other forms of entry.

${ }^{11}$ Aghion et al. (2005c) use the following sequential game between incumbent firms and potential entrants to provide foundations for this assumption. The entrant must pay a small entry fee to enter and can decide whether to pay this fee after observing the post-innovation technology of the incumbent. Assuming that Bertrand competition takes place after entry, the entrant will find it profitable to pay the entry fee and appropriate the local market if the incumbent is expected to lag behind the entrant. If the incumbent is, instead, expected to compete on an equal footing with the entrant, then the entrant will find it optimal not to pay the entry fee.
} 
incumbents.

\subsection{Equilibrium innovation}

Consider the $R \& D$ decisions of incumbent leaders in state- 1 and state- 2 sectors. ${ }^{12}$ Denote by $p_{j}$ the probability that the potential entrant pays the cost of entry in a state- $j$ sector. This probability depends negatively upon a common entry cost parameter $\Lambda: p_{j}^{\prime}(\Lambda)<0$ (see Appendix A.1).

- A state-2 leader, with $A_{t-1}(i)=\bar{A}_{t-2}$, chooses its investment $z$ to maximize the expected net profit gain from innovation minus the R\&D effort cost, that is:

$$
\max _{z}\left\{\delta z\left(1-p_{2}\right) \bar{A}_{t-1}-c\left(z^{2} / 2\right) \bar{A}_{t-2}\right\}
$$

from which the first order condition yields:

$$
z=(\delta / c)\left(1-p_{2}\right) \gamma=z_{2}
$$

In words, the type-2 leader only retains the market if it successfully innovates and there is no entry (i.e. with probability $z\left(1-p_{2}\right)$ ). If it does not innovate then its automatically upgraded type-3 rival catches up with it, and Bertrand competition between the two neck-and-neck firms dissipates all profits.

- A state-1 leader, with $A_{t-1}(i)=\bar{A}_{t-1}$, chooses its innovative investment to:

$$
\max _{z}\left\{\delta\left[z \bar{A}_{t}+(1-z)\left(1-p_{1}\right) \bar{A}_{t-1}\right]-c\left(z^{2} / 2\right) \bar{A}_{t-1}\right\}
$$

Hence, from the first order condition we get:

$$
z=(\delta / c)\left(\gamma-1+p_{1}\right)=z_{1}
$$

In words, the type-1 leader retains the market when: (i) it successfully innovates or (ii) it does not successfully innovate and there is no entry.

\footnotetext{
${ }^{12}$ Recall that laggards do not innovate and type-3 firms are automatically upgraded without investing.
} 


\subsection{The "escape entry" and "discouragement" effects}

Now consider the effects of increasing entry threat on innovative activity, which we here model as a reduction in the entry cost parameter $\Lambda$. In state- 3 sectors an increase in the entry threat has no effect on innovation investments, since those are always equal to zero. Now, consider what happens in state- 2 and state- 1 sectors:

- In state- 2 sectors, a reduction in $\Lambda$ that increases the entry threat $p_{2}(\Lambda)$, reduces the expected payoff from innovating and therefore "discourages" innovation. Firms further behind the frontier know that they cannot survive entry, even if they successfully innovate. That is:

$$
\frac{\partial z_{2}}{\partial \Lambda}=-(\delta / c) \gamma p_{2}^{\prime}(\Lambda)>0
$$

This discouragement effect is similar to the Schumpeterian appropriability effect of product market competition pointed out, for example, in Aghion et al. (2001, 2005a).

- In state- 1 sectors, a reduction in $\Lambda$ that increases the entry threat $p_{1}(\Lambda)$, fosters innovation as it increases the incumbent leaders' losses from entry if they do not innovate, thereby increasing their incentive to "escape entry" by innovating. That is:

$$
\frac{\partial z_{1}}{\partial \Lambda}=(\delta / c) p_{1}^{\prime}(\Lambda)<0
$$

This escape-entry effect is similar to the escape-competition effect pointed out in Aghion et al. (2001, 2005a).

Together with the fact that laggards never innovate, this implies that an increase in the threat of entry discourages innovation in a state- 2 sector and encourages it in a state- 1 sector. Expected productivity growth in either sector is proportional to innovative investment:

$$
E\left[\left(\frac{A_{t}(i)-A_{t-1}(i)}{A_{t-1}(i)}\right) \mid A_{t-1}(i)=\bar{A}_{t-j}\right]=z_{j}(\gamma-1)=g_{j}, j \in\{1,2\}
$$


Therefore a reduction in entry cost $\Lambda$ has a positive escape-entry effect on incumbent productivity growth in state-1 sectors, and a negative discouragement effect in state- 2 sectors: ${ }^{13}$

$$
\frac{d g_{1}}{d \Lambda}=\frac{d z_{1}}{d \Lambda}(\gamma-1)<0 ; \quad \frac{d g_{2}}{d \Lambda}=\frac{d z_{2}}{d \Lambda}(\gamma-1)>0
$$

\subsection{Empirical implications}

In summary, the main empirical implications that we draw from the theory are:

- Increasing the threat of entry has a positive effect on incumbent innovation in sectors that are close to the technological frontier and a possibly negative effect in sectors that are further behind the frontier.

- Increasing the threat of entry has a more positive effect on incumbent productivity growth in sectors that are closer to the technological frontier than in sectors that are further behind the frontier.

\section{Empirical specification}

The implications derived above explain a heterogeneous pattern of entry effects on incumbent performance along the distance to technological frontier. The descriptive evidence in Figure 1, however, is not sufficient to establish a causal relationship. The central empirical relationship that we want to explore is of the form:

$$
Y=f(P, D, X)
$$

where $Y$ is a measure of incumbent performance, $P$ is entry threat, $D$ is the distance to the technological frontier, and $X$ is a vector of further covariates. These covariates may determine the performance of incumbents in addition to entry - most important, we think of

\footnotetext{
${ }^{13}$ In state-3 sectors an increased entry threat does not affect the rate of productivity growth. Being upgraded with probability one, both firms in such sectors grow at the same constant rate $\gamma-1$. Thus:

$$
g_{3}=\gamma-1,
$$

and a reduction in entry cost $\Lambda$ has no effect on productivity growth.
} 
effects triggered by trade relations and other factors that affect competition, market structure and the rents of incumbents.

Our main measure of incumbent performance is growth of total factor productivity $\left(\Delta T F P_{i j t}\right)$ measured on establishment level. To bring equation (6) to the data we specify the relation between incumbent TFP growth and entry as

$$
\Delta T F P_{i j t}=\alpha+\beta_{1} E_{j t-1}+\beta_{2} D_{j t-1}+\beta_{3} E_{j t-1} D_{j t-1}+X_{i j t-1}^{\prime} \gamma+\tau_{t}+\eta_{i}+u_{i j t} .
$$

where $i$ indexes incumbent establishments, $j$ indexes industries, and $t$ indexes years. While entry threat $P$ is unobservable, actual entry $E$ and variables affecting entry costs $\Lambda$ can be observed. We use lagged actual entry $E_{j t-1}$ directly in equation (7) and instrument it with policy reforms that change entry costs $\Lambda$ building on the following economic reasoning. If entry threat were observable and we could use it directly in equation (7) it would be potentially endogenous, i.e. depend on incumbent innovation that triggers productivity growth (see equation (11) in Appendix A.2). When using observable actual entry as proxy for entry threat we face the same problem, only in aggravated form. Actual entry deviates from entry threat in situations where entrants may lose against incumbents, that is, in our context, in industries close to the frontier. In industries further behind the frontier, where entrants can never lose against incumbents, actual entry and entry threat are identical (see equation (13)). If entry threat and actual entry differ, then the difference depends again on incumbent innovative activity (see equation (14)). It can be shown that entry threat correlates positively with actual entry as long as incumbent innovation aiming at escaping entry is not too successful in the sense of entry prevention to outweigh the direct positive effect of entry threat on actual entry (see Appendix A.2).

Due to the described endogeneity problem we expect a negative covariance between actual entry and the error term in incumbent performance equations. Including establishmentspecific fixed effects and time effects is unlikely to be sufficient to address the endogeneity issue, since industry-specific, time-varying changes of incumbent performance should affect actual entry. Even using a lagged entry measure, as we do, may not fully solve the problem. 
Our preferred approach is to control for endogeneity by using selected policy reforms as instrumental variables (IV). We argue that these reforms changed entry costs and effected entry threat as well as actual entry differentially across industries and time but, conditional on all other covariates in the model, do not effect TFP growth or innovation. The policy instruments include time-varying indicators of the implementation of the EU Single Market Program (SMP) in industries with medium or high entry barriers that were likely to be reduced by the SMP, competition investigations by the UK Competition Authority that culminated in entry-inducing remedies, and large scale privatizations. ${ }^{14}$

Potential endogeneity of the distance to the technological frontier is also a concern since any assumption we impose on that variable can directly affect findings on heterogeneous entry effects along the distance to frontier. To address this issue we use US technology and production information as additional instruments. ${ }^{15}$

Our preferred specification of equation (7) includes linear terms of the entry and distance to frontier measures, as well as their continuous interaction term. We show that our results are robust to using alternative functional forms in section 5 (specifically, interacting entry with discrete distance to frontier indicators). To control for different permanent levels of TFP growth across establishments we include individual fixed effects $\eta_{i}$. Common macro shocks are captured by time dummies $\tau_{t}$.

A concern about using TFP growth in incumbent establishments in our context is that it may not only reflect firms' innovative activity, but also advances due to imitation of entrants with superior technology or reallocation within establishments. To check whether our TFP growth results are likely to pick up actual changes in firms' innovative activity we also estimate patent count models to complement our TFP growth estimations. We specify the innovation rate as

$$
n_{i j t}=e^{\alpha+\beta_{1} E_{j t-1}+\beta_{2} D_{j t-1}+\beta_{3} E_{j t-1} D_{j t-1}+X_{i j t-1}^{\prime} \gamma+\tau_{t}+\eta_{i}},
$$

\footnotetext{
${ }^{14} \mathrm{~A}$ full description of the policy instruments are given in Table B.1, App. B.

${ }^{15}$ Summary statistics on these variables can be found in Table B.4, App. B.
} 
where $i$ indexes incumbent firms, $j$ indexes industries, and $t$ indexes years. The patent process is assumed to follow a flexible negative binomial distribution with hazard rate $n_{i j t}$. All other variables and parameters are defined as in equation (7), and the specification is similar. To take unobservable firm-specific, time-invariant heterogeneity in patent behavior into account we follow Blundell et al. (1999) and use pre-sample information on firms' knowledge stocks.

In the linear model in (7) we apply IV estimation that involves three first stage regressions: one for the linear entry term, one for the distance term as well as one for their interaction. In the non-linear case of (8) we use the control function approach to control for endogeneity. This approach consists of including the three first-stage residual terms in the regression equation. $^{16}$

Our identification strategy rests on using actual entry directly in equations (7) and (8) and instrumenting it with policy interventions that affected the ease and cost underlying entry threat and actual entry, and did so differentially across industries and time. For example, the aims of the SMP were to bring down EU internal barriers to the free movement of goods, services, capital and labor by interventions such as harmonizing product standards, indirect taxes and border controls, removing national requirements and other non-tariff barriers that enable firms to segment markets and limit competition, removing public sector discrimination in favor of its own firms, reducing capital and labor costs by permitting free flow across countries. The interventions may also affect innovation incentives and productivity growth through other channels, especially through changing the competitive environment. Thus, we pay careful attention to controlling for measures of competition and import penetration, and argue that the entry instruments have no additional impact on innovation and TFP growth, after we condition on these covariates. We test the overidentification assumptions and experiment with using only subsets of these instruments. In section 5 our results are shown to be robust to these specification checks.

\footnotetext{
${ }^{16}$ In linear models, control function and IV coefficient estimates coincide. See Wooldridge (2002), Chapter 18 or Blundell and Powell (2003).
} 


\section{Data}

We combine micro-level data from several sources. To measure entry we use data on the population of manufacturing plants in Great Britain provided by the UK Office for National Statistics (ONS) in connection with the Annual Respondents Database (ARD). The ARD is the most comprehensive establishment-level dataset for Great Britain and is collected by the ONS under the 1947 Statistical Trade Act. This makes it a legal obligation for firms to report. Time-varying ownership information allows us to quantify firm entry into the UK at the 4-digit industry level. To measure growth of total factor productivity we can use information on output and inputs for the random stratified ARD sample of establishments from the population. ${ }^{17}$

We also use firm-level accounting data from DataStream that is matched to patent data from the NBER/Case Western Patent database for a sample of firms listed on the London Stock Exchange (LSE). Using data on patents at the US Patent Office has the advantage of focusing on major patents by UK firms, since their low value patents are usually not taken out in the US. The firms in our sample account for a large proportion of UK R\&D activity. ${ }^{18}$

\subsection{Total factor productivity growth and innovation}

To calculate TFP growth we apply a standard factor share approach, use superlative index measurement (Caves et al. 1982a, b), and data from the ARD on output and inputs of establishments in 180 4-digit manufacturing industries between 1987 and 1993. We pay attention to a number of potential measurement errors in TFP (see Appendix B) and present results using two alternative TFP growth measures as well as labor productivity growth. We also consider a patent count variable as an additional measure of performance. The data set on firms listed on the LSE and their patenting activity at the US Patent Office covers 60 different 3-digit manufacturing industries between 1987 and 1993.

\footnotetext{
${ }^{17}$ About 76 percent of all sampled establishments between 1980 and 1993 are single plants, all others represent groups of on average 1.6 plants operating in the same 4-digit industry and owned by the same firm.

${ }^{18}$ See also Appendix B on data sources.
} 


\section{$4.2 \quad$ Entry}

When calculating entry measures we can distinguish between foreign firm and domestic firm entry. Our measure for technologically advanced entry as focussed on in the theory section is the foreign firm entry rate. We choose foreign entry since it is from firms that operate internationally and most likely produce at the technological frontier. Moreover, foreign firm entry is an important form of entry in the UK during the 1980s and 1990s. Inflows of foreign direct investment were substantial during that period, and the employment share in foreign owned manufacturers rose from 9.97 in 1980 to 16.14 percent in 1993 . We define the foreign firm entry rate as the share of industry employment that is in foreign firms entering the respective British industry for the first time with a newly set-up production facility:

$$
E_{j t}=\frac{\sum_{i=1}^{N_{j t}} L_{i t} * D_{i j t}(\text { new facility; owner }=\text { foreign }, \text { new })}{\sum_{i=1}^{N_{j t}} L_{i t}},
$$

where $L_{i t}$ is the number of employees in plant $i$ in year $t$. The function $D($.$) equals one$ if a foreign firm enters industry $j$ with a new plant in year $t$ and does not own any older plants in industry $j$, and zero otherwise. ${ }^{19}$ The denominator is the number of employees in all plants in industry $j$ at time $t$. For the productivity growth models we use the measure at the 4-digit industry level (SIC code) and for the patent count models at the 3-digit SIC code level.

The domestic firm entry rate is calculated in a similar manner and its effects on incumbent productivity growth and patenting activity are investigated in section 5.3.2.

Our entry measures capture the size of foreign or domestic entry and thus go beyond simply counting entrants or simply considering all entering firms in one measure. The foreign firm entry rate, moreover, is a more direct entry measure than macro data on cross border financial flows, which are often used to measure FDI. In contrast to micro-data measures based on the share of industry employment in all foreign-owned production units ${ }^{20}$ our

\footnotetext{
${ }^{19}$ If a foreign firm enters industry $j$ simultaneously with more than one new plant in year $t$ then employment in all these plants is counted, but any form of firm expansion after the year of entry is excluded.

${ }^{20}$ See, for example, Aghion et al. (2004), Griffith et al. (2002) and Haskel et al. (2002).
} 
measure focuses precisely on entry and separates it out from employment expansion or contraction of existing foreign firms and from reallocation between domestic and foreign owners via takeover activity.

\subsection{Distance to frontier}

We measure the distance of each UK industry to the industry-specific technological frontier using two alternative metrics for technology. In the context of the productivity growth models we use disaggregated measures where each 4-digit UK industry is compared to a matched 4-digit US industry. ${ }^{21}$ For the patent count models we use disaggregated measures on the 3-digit SIC code level. Our main measure for UK industry $j$ in year $t$ is the relative labor productivity measure

$$
D_{j t}=\frac{1}{3} \sum_{z=0}^{2} \ln \frac{\left(Y^{U S} / L^{U S}\right)_{j t-z}}{\left(Y^{U K} / L^{U K}\right)_{j t-z}}
$$

where $Y$ denotes real output and $L$ employment. Since we observe output and input data for the pre-sample period we can use a lagged three year moving average to mitigate the effects of measurement error on the time variation of the distance variable. The second measure we use is a superlative index relating TFP in each US industry to TFP in the corresponding UK industry. Our empirical results in section 5 are shown to be robust to introducing this second measure and to instrumenting both distance to frontier variables. Results are also similar if we use and instrument discretised versions of the continuous distance variables where we simply group industries close to and far from the technological frontier.

US industries are chosen as a reference point for the following reasons - the US represents the technological frontier in a large number of industries, it is often ahead of the UK, ${ }^{22}$ and a large share of foreign entrants in Britain are US-owned. ${ }^{23}$ To calculate the distance to frontier measure we matched data on US 4-digit industries from the NBER manufacturing

\footnotetext{
${ }^{21}$ See App. B for details on the matching of UK and US industries.

${ }^{22}$ See, inter alia, Griffith et al. (2004).

${ }^{23}$ For the time period 1986 to 1992 our data shows that, on average, 34 percent of all foreign greenfield entrants in British manufacturing industries are under US ownership.
} 
productivity database and the ARD data on domestic incumbent establishments in Britain aggregated to the 4-digit industry level. ${ }^{24}$

British 4-digit industries differ considerably in their distance to the industry-specific frontier as illustrated in Table B.2, App. B. The table lists the 10 largest industries above and below the median distance to frontier. The sample distribution of the distance measure is such that about 20 percent of all industry-year observations are at or close to the frontier, while another 20 percent of industries are more than 40 percent behind their US counterpart. In the context of our study, high variation of the distance measure is crucial given our interest in heterogeneity of entry effects along the distance to frontier distribution.

Another important prerequisite for our empirical analysis is variation of entry rates across industries with different distance to the industry-specific frontier. We checked that all four quartiles of the distance distribution cover industry-year observations where no, some or substantial foreign entry occurs. In addition, comparing the quartile-specific distributions of the entry rate, the number of employees in entering firms and entrants' size we see in Table B.3, App. B considerable overlap of these distributions.

\subsection{Descriptive statistics}

Our sample for the estimation of productivity growth models is an unbalanced panel of 23,802 observations on 4,947 domestic incumbent establishments in 180 4-digit industries, 1987 to $1993 .^{25} 81$ percent of these establishments are older than 10 years when they enter the sample. They have on average 274 employees, real output of $£ 15 \mathrm{~m}$ in $1980 £$, and experience TFP growth of on average -0.8 percentage points. This negative average growth reflects the recession in the early 1990s; the corresponding figure up to 1990 is 1.3 percentage

\footnotetext{
${ }^{24}$ App. B provides details on the matching of UK and US industries. The ARD and NBER databases contain data collected by national statistical agencies in each country using similar methods, and the data on value-added and numbers employed use very similar definitions (see App. B for references). To the extent that the definitions may vary across countries, this should be controlled for by industry and time fixed effects. We use labor productivity as our main measure as this is not affected by differences in the way capital is measured across the two datasets. However, we show that our results hold when using a TFP-based measure (see section 5).

${ }^{25}$ See Appendix B on sample construction.
} 
points.

To estimate the patent count models we use an unbalanced panel of 1,085 observations on 176 incumbent firms in 60 3-digit industries, 1987 to 1993. 74 percent of the firms were listed on the LSE for more than a decade when entering the sample. They employ on average about 8,549 people, have average real sales of $£ 443 \mathrm{~m}$ in $1980 £$ and about 60 percent take out at least one patent at the US Patent Office between 1987 and 1993. As typically found, the distribution of patent counts is highly skewed - many firms in our sample do not patent, some patent a little and a small number of firms are granted many patents per year.

Further details on data sources, sample construction and descriptive statistics are given in Appendix B.

\section{Empirical results}

To investigate the economic mechanism behind the descriptive evidence in Figure 1 we estimate productivity growth, as well as patent count models, where we control for confounding factors and take endogeneity of entry and distance to frontier measures into account. Then, we analyze how measurement issues and the key theoretical assumption on entry affect our results. We conclude by explaining why the most likely alternative interpretations based on knowledge spillovers do not fully explain our empirical findings.

\subsection{Growth of total factor productivity}

To start with, we analyze the average effect of entry on subsequent total factor productivity (TFP) growth among incumbents in more restrictive models than equation (7). All regressions in Table 1 include a full set of year and establishment-specific fixed effects. Standard errors are clustered on the industry level and observations are weighted by employment and the inverse of their sampling probability. ${ }^{26}$

\footnotetext{
${ }^{26}$ See Moulton (1990) on standard error clustering. Observation weights and the sampling scheme are described in Appendix B.
} 
[Table 1 here]

In column (1) we use a linear term of the lagged foreign firm entry rate (as defined in section 4.2) and find a positive and significant effect on subsequent TFP growth of domestic incumbent establishments. We checked that the coefficient of the entry rate is driven by changes in the number of new employees in entering foreign firms, rather than changes in the number of all employees in the industry. ${ }^{27}$

In column (2) we include three additional covariates - distance to the frontier, import penetration and competition - and show that the average entry effect is robust to controlling for these factors. High values of the lagged distance measure indicate industries that are far from the industry-specific frontier (see section 4.3 for the distance definition). The positive and significant coefficient indicates higher growth rates for domestic incumbents in industries that are far from the frontier than in those close to it. We will return to this result in section 5.3.3.

Foreign firms can enter local product markets through imports, as well as by building up local production capacity. We pay less attention to this alternative form of entry, mainly because we have much less disaggregated import data. We control for lagged import penetration and find a positive and significant effect on subsequent TFP growth in domestic incumbent establishments, however, it has little impact on the coefficient of foreign firm entry. To capture the influence of other rent-affecting processes we use the lagged rent-based competition measure described in Appendix B. It is calculated at the 4-digit industry level, varies between 0 and 1 and takes the value of 1 in case of perfect competition. In line with previous work, inter alia Nickell (1996), we find a positive and significant coefficient.

In columns (3) and (5) we address the core endogeneity issues. As stated above, we expect a negative covariance between actual foreign firm entry and the error term in our TFP growth model, since foreign firms can more easily realize entry into markets when their

\footnotetext{
${ }^{27}$ In a regression with both elements of the entry rate included separately the coefficient (standard error) of the numerator, the number of entering employees, is positive and significant $(0.017(0.005))$ while the coefficient of the denominator is small and insignificant $(0.0003$ (0.0002)).
} 
relative advantages are high and they anticipate this correctly. This is where productivity growth and innovative activity of incumbents is weak and, thus, their chances to escape and prevent entry are small. Note here, that the opposite expectation is often expressed, but not confirmed in the literature of foreign direct investment: Foreign entrants may be attracted by high growth perspectives of domestic incumbents and anticipate these correctly such that a positive covariance between the entry variable and the error term in incumbent performance equations would result. Attenuation bias (towards zero) in an OLS regression could also be caused by measurement error. In the IV regression in column (3) we use as instruments variables on product market policy changes that influence entry costs and, thus, effected entry threat and actual entry differentially across industries and time (see also section 3). Statistics from the first stage regression of entry on the excluded policy instruments and all other exogenous variables are shown at the bottom of Table $1 .^{28}$ The instruments are powerful, the F-test indicates their joint significance. ${ }^{29}$ No rejection of the overidentifying restrictions is implied by the $\chi^{2}$-test result, and this also provides statistical support for the overall set of policy instruments. We can show that the significant, positive entry effect is stable with respect to many changes of the model specification and the set of instruments. ${ }^{30}$

The F-test for the exogeneity of the entry term rejects the exogeneity of actual foreign firm entry and highlights the importance of instrumenting. Since the IV coefficient on the

\footnotetext{
${ }^{28}$ In all first stage regressions we impose the same coefficient for all individual monopoly cases where the coefficients were not statistically different from each other in intermediate versions of the first stage regressions. Analogous restrictions are used in case of merger, privatization and SMP indicators. In addition, we aggregate highly correlated policy dummies that relate to the same industry. The first stage entry regression in column (3), thus, includes 11 separate instrumental variables.

${ }^{29}$ When calculating standard errors and test statistics we take into account that our dependent variables in first stage regressions are measured at the industry level.

${ }^{30}$ For example, if we exclude all privatization instruments, we find the following entry coefficient (standard error): 2.896 (0.292). When, in turn, excluding the instruments that belong to one of the other groups of policy changes (monopoly cases, merger cases, SMP introduction) the entry coefficients are all positive, significant and quite stable. They vary between 2.920 (0.362) and 3.841 (2.102). In all four model variants with reduced instrument sets, these sets are jointly significant on the first stage and overidentification tests never reject.

When we change the model specification to include industry-specific instead of establishment-specific fixed effects the entry coefficient (standard error) is: 3.089 (0.314). When controlling for lagged establishmentspecific sales market shares instead of using the rent-based competition measure the entry effect estimate is: $2.642(0.275)$.
} 
foreign firm entry rate is larger than the OLS estimate, a negative bias is found, and this is in line with our expectation of a negative covariance between entry and the error term in our TFP growth model. It may also reflect an attenuation bias (towards zero) in the OLS regression caused by measurement error.

The positive average impact of the direct foreign entry measure we use here on incumbent TFP growth is in line with the results we find in Aghion et al (2004). There we use British data for a longer time period and a less direct, noisier entry measure, i.e. the change of the industry employment share in all foreign firms, not only in entrants. ${ }^{31}$ Our finding is also consistent with the average incumbent productivity growth prediction that can be derived from our theoretical model for plausible parameter assumptions (see Appendix A.3). However, it is important to note that this is neither an unconditional implication of the theory set out in section 2 , nor is it in line with the empirical evidence from several studies of foreign direct investment or liberalization reforms. ${ }^{32}$

Thus, we allow for more flexibility in the relation between foreign firm entry and productivity growth to see whether there is systematic heterogeneity of entry effects along the industry- and time-varying distance to the industry-specific technological frontier. To do this we estimate equation (7) including the continuous interaction of the entry and distance to the frontier measures.

When including the interaction term, the coefficients of the linear entry and distance terms in column (4) remain positive and significant, as before. The interaction is negative and significant. In industries that are far away from the frontier the positive effect of entry is now counteracted by the negative interaction effect. Thus, productivity growth of domestic incumbents responds more positively to technologically advanced entry in industries close to the technological frontier than in industries farther below the frontier and this provides first support for the second empirical implication from the theory in section 2 .

\footnotetext{
${ }^{31}$ See also Griffith et al. (2002) and Haskel et al. (2002).

${ }^{32}$ For example, Javorcik (2004) and Aitken and Harrison (1999).
} 
Similar results arise when we control for endogeneity of entry and the distance to frontier in column (5). We now have three first stage regressions, one for the linear entry term, one for the linear distance term and one for the interaction term. Taking potential endogeneity of the distance measure into account is important since any assumption we impose on that variable directly feeds into our main finding of heterogeneous entry effects. In addition to policy instruments we use as further instruments measures of the production and technology structure in US industries that are significantly correlated with the distance measure, but which can be assumed not to depend directly on anticipated UK TFP growth developments. We identify two such variables: the capital-labor ratio and average real wages among skilled workers in US 4-digit industries at the beginning of the time period relevant for distance measurement..$^{33}$

The F-tests in the bottom panel of Table 1 shows that the set of instrumental variables has explanatory power in all three first stage regressions. The $\chi^{2}$-test indicates no rejection of the overidentifying restrictions. The F-test of joint exogeneity of all instrumented terms in the second stage regression is rejected and, thus, taking endogeneity into account matters. We find a negative and significant interaction term in column (5) and positive and significant coefficients on the linear terms for entry and distance to frontier. Again we can show that the results are stable with respect to changing the model specification as above and varying the set of instruments. ${ }^{34}$

The estimation results above strongly indicate heterogeneity in the impact of foreign firm entry on subsequent TFP growth in domestic incumbent establishments, depending

\footnotetext{
${ }^{33}$ To capture the effect of US technology on the distance of UK industries to the frontier we also tried research and development intensities in 2-digit US industries and the US ratio of skilled over all workers in 4-digit industries. However, both these variables turned out to have no explanatory power in first stage distance regressions. This finding deviates from what we find in the firm sample used for patent count models below.

${ }^{34}$ Most important, we find stable results if we vary the main instrument set by excluding in turn privatization, monopoly, merger or SMP instruments. The second stage estimates for the linear entry coefficient then vary between 3.864 (2.544) and 4.823 (1.621) and those for the distance term between $0.077(0.051)$ and 0.088 (0.043). The interaction estimates take values between -8.387 (3.111) and -10.957 (7.751). In each model, both entry-related coefficients (linear and interacted) are jointly significant at the $1 \%$-significance level. Moreover, the reduced instrument sets are always significant on the first stage and overidentification tests never reject.
} 
on the industry's distance to the frontier, and a positive average impact. But what about the economic significance of these effect estimates? To see that we calculate the impact of increasing the entry rate by one standard deviation in the sample ( 0.5 percent) on subsequent incumbent TFP growth at the 10\%, 50\% and $90 \%$ percentile of the sample distance to frontier distribution. In industries at the median distance to frontier an increase of the foreign firm entry rate by one standard deviation raises TFP growth in domestic incumbent establishments by 1.4 percentage points. ${ }^{35}$ In industries far from the frontier, i.e. at the 90\%-percentile of the distance distribution, the TFP growth effect is -0.3 percentage points and close to the frontier (10\%-percentile) the effect is 3.1 percentage points. Since the mean of TFP growth in the sample is -0.8 percentage points, and the standard deviation is 11.3 percentage points, these estimates are economically significant and their variation along the distance to frontier distribution is reasonable. All in all, the results in columns (4) and (5) of Table 1 consistently show that the threat of technologically advanced entry in industries close to the frontier triggers subsequent TFP growth among incumbents and can discourage it in industries far from the frontier.

\section{$5.2 \quad$ Patenting}

The TFP growth evidence shown above provides support for the idea that entry spurs incumbents to invest in innovation, particularly when they are near the technological frontier. Lingering concerns are, however, that TFP growth may not only reflect entry-induced innovative activity, but also entrant imitation or that TFP growth may be driven by reallocation between plants within incumbent establishments. In order to explore the relation between entry and innovation more directly we estimate patent count models that are specified in a similar manner as the TFP growth models. While using an entirely different dataset to measure firm-level innovation (see section 4) we find a strikingly similar pattern of results.

\footnotetext{
${ }^{35}$ This median effect based on column (5) is equal to the average effect since the sample distance distribution is unskewed. Moreover, the result of 1.4 is similar to the impact of 1.5 that is implied by the model in column (3) with a linear entry term only.
} 
[Table 2 here]

In Table 2 we present estimates from negative binomial models that allow for overdispersion of the patent count variable and include time as well as 3-digit industry fixed effects. We capture unobservable firm-specific, time-invariant heterogeneity of patenting behavior by exploiting rich pre-sample patent data. Following Blundell et al. (1999) we add as explanatory variables two proxies for a firm's technological knowledge stock: the firm-specific pre-sample patent stock and an indicator for non-zero pre-sample patent stock values. As expected, the coefficients on both these variables are found to be significant and positive.

In line with what we find in the TFP growth regressions, the foreign firm entry rate has a positive and significant average effect on subsequent patenting at the US patent office by incumbents listed on the London Stock Exchange, and this holds up to controlling for other factors, changing the model specification and, most importantly, controlling for the endogeneity of entry. As in column (3) of Table 1, the set of policy instruments is jointly significant in the first stage entry regression in column (3), Table 2. The residual from this first stage regression, when used as control function in the second stage regression, has a significant, negative coefficient indicating a negative bias in the non-instrumented entry coefficient and this is robust to several tested changes of the model specification or the instrument set. ${ }^{36}$

The estimated effects of other factors are similar to our results for TFP growth models, and consistent with other findings in the literature. We again find a positive and significant coefficient for the distance to the industry-specific frontier. The inverted U-relationship we observe for competition and patent counts is in line with Aghion et al. (2005a). When controlling for import penetration, we find positive, but weak effects, as in Blundell et al. (1999) or Disney et al. (2003b).

\footnotetext{
${ }^{36}$ When we change the set of instruments, as explained in subsection 5.1, we find significant, positive entry effects in all four model variants with reduced instrument sets. The respective instrument sets are jointly significant in the first stage and the second stage entry coefficients (standard errors) vary between 26.542 (15.877) and 45.956 (13.473).
} 
In column (4) we explore the heterogeneity of foreign firm entry effects on subsequent incumbent innovation activity along the industry- and time-varying distance to the industryspecific frontier. As in TFP growth models, we find a negative and significant interaction term and positive and significant coefficients of the linear entry and distance to frontier terms. Thus, the positive effect of the linear entry term gets increasingly counteracted by the negative interaction effect the farther away the industry is from the technological frontier. This pattern provides support for the first empirical implication in section 2 .

When we control for endogeneity of actual foreign firm entry and distance to frontier in column (5) of Table 2 we estimate first stage regressions for the linear entry term, the linear distance to frontier term and their interaction. The $\chi^{2}$-test results in the lower part of Table 2 show that the set of policy and US instruments we use has explanatory power in all three first stage regressions. ${ }^{37}$ Joint exogeneity of all instrumented terms is rejected in the second stage regression. The pattern of our estimates remains robust to several tested changes of the model specification and the set of instruments. ${ }^{38}$

The economic magnitude of the estimated effects also varies in a similar way along the sample distance to frontier distribution, as in the corresponding TFP growth model. In industries at median distance an increase of the foreign firm entry rate by one standard deviation (0.4 percent) raises the number of patents that incumbents take out subsequently by 6 percent, i.e. from the mean patent number of 8.1 to 8.6. In industries far from the frontier (90\%-percentile) the subsequent patent number is reduced to 7.3 patents and close to the frontier (10\%-percentile) it increases to 11.0 patents. The latter increase is equivalent to about 12 percent of the patent count standard deviation in the sample (24.1 patents) and,

\footnotetext{
${ }^{37}$ We use as measures of the production and technology structure in US industries: the ratios of capital over labor and of skilled over all workers in 4-digit US industries as well as research and development intensities in 2-digit US industries. In addition we use all seven interaction terms between the US-related and policy instruments that turned out to be significant in the distance-related first stage regression.

${ }^{38}$ Most important, we vary the set of instruments as for the TFP growth model in column (5), Table 1. The respective reduced instrument sets have explanatory power on the first stage and the two second stage entry-related coefficients are always jointly significant at the $2 \%$-significance level. The linear entry coefficient takes values between 37.159 (12.558) and 73.645 (40.757), the linear distance term between 1.744 (0.356) and $3.296(0.746)$ and the interaction coefficient between -109.856 (51.515) and -233.974 (168.939).
} 
thus, the findings are reasonable.

Altogether, the patent count results suggest that a major driving force of the entry effects in our TFP growth estimations is incumbent innovation, not just imitation or reallocation.

\subsection{Robustness}

So far, we have presented empirical results that support the finding in Figure 1 and the theoretical interpretation put forward in Section 2. We used data on productivity growth and patenting of incumbents coming from different sources and showed robustness of the results to several changes of the model specification and instrumentation strategy. In this section we explore the robustness of our results in three other directions. First, we consider potential influences of measurement error. Secondly, we relax the key theoretical assumption that foreign firms always enter at the technological frontier and investigate effects of the domestic firm entry rate in that context. Third, we argue why the two most likely alternative interpretations based on knowledge spillovers do not fully explain our empirical findings.

\subsubsection{Measurement issues}

There are three forms of measurement error that concern us here - (i) measurement of dependent variables, (ii) measurement of the distance to the frontier, (iii) the consequences of using an unbalanced panel. We consider these in turn.

The standard factor share approach we use here to calculate TFP growth instead of estimating it has the advantage of involving the use of a superlative index building on a flexible translog production function. A usual concern, however, is that it relies on the assumption of perfect competition in factor and product markets. In case of imperfectly competitive product markets the level of TFP will systematically be overstated, ${ }^{39}$ and if the impact of reducing entry barriers is accompanied by increasing competition, this would imply underestimating TFP growth. Thus, it is important to consider whether our results are robust to relaxing this assumption. We calculate an alternative measure of TFP growth

\footnotetext{
${ }^{39}$ See, inter alia, Klette and Griliches (1996).
} 
that takes imperfect competition into account (see Appendix B). When using the alternative measure we again obtain positive and significant coefficients for entry and the distance to frontier and a negative and significant coefficient for the interaction term. Using labor productivity growth also gives similar results. ${ }^{40}$

Our second concern is with measurement of the distance to the frontier. In section 4.3 we introduce an index that relates labor productivity in 4-digit UK industries to labor productivity in corresponding 4-digit US industries as our preferred measure because it is not affected by capital stock measurement in the two relevant data bases. However, the results remain robust when using a relative TFP index that is also measured on the 4-digit industry level in columns (1) and (4) of Table 3. In addition to varying the index, we deviate from our preferred specification here: we interact entry with two dummies respectively indicating industries near or further behind the frontier, use as well the linear continuous distance to frontier term, and instrument all three terms. We find that both TFP growth as well as patent count regressions support the conjecture that entry threat spurs incumbents to invest in innovation most in industries near the technological frontier.

[Table 3 here]

Finally, we want to clarify that our results do not depend on poor performing incumbents that are driven out of the market by entrants and the subsequent reallocation of resources. We eliminate establishments and firms that drop out of our panels and show the respective TFP growth estimation in column (3) and the patent count estimation in column (6) of Table 3. The results are found to hold as well for these subsamples.

\footnotetext{
${ }^{40}$ Using the alternative TFP growth measure leads to a coefficient (standard error) of -6.771 (2.872) for the interaction, 4.175 (0.422) for the linear entry and 0.088 (0.043) for the distance terms. Using labor productivity gives as estimates for the interaction, linear entry and distance terms: -8.308 (3.923), 2.381 (0.898), 0.289 (0.124). In both models the set of instruments is jointly significant on the first stage and overidentification tests do not reject.
} 


\subsubsection{Entry behind the technological frontier}

In the empirical analysis above we focused entirely on foreign firm entry. Since foreign entry is from firms that operate internationally, and are more likely to produce at the technological frontier than other entrants in the UK, this accords well with considering technologically advanced entry in our theory section 2 , where we assumed that entry takes place at the new frontier $\bar{A}_{t}$.

Alternatively, we can explore the case where entrants have productivity $\bar{A}_{t-1}$ instead of $\bar{A}_{t}$ using our theoretical framework. This case leads to the main conclusion that increasing the threat of entry encourages innovation and productivity growth in sectors that are at intermediate distance from the frontier; it discourages innovation in sectors that are far below the frontier; and it has little effect on innovation in sectors close to the frontier. In the case where entrants have productivity $\bar{A}_{t-2}$ or are even further behind the frontier, no effects on innovation and productivity growth are to be expected..$^{41}$

This prediction can explain the empirical results we find when exploring the effects of the domestic firm entry rate on subsequent incumbent TFP growth or patenting. Coefficient estimates for domestic entry terms always turn out to be insignificant in our models. See, for example, columns (2) and (5) in Table 3 and note that the coefficients of the foreign firm entry terms remain very similar to those in columns (5) of Tables 1 and 2. The insignificant coefficients for domestic entry terms are in line with the following findings from the literature on firm entry and new firm performance: ${ }^{42}$ The average domestic entrant is likely to struggle with survival during its initial period after market entry, is occupied with learning about its own productivity and market conditions and is usually very small compared to foreign entrants or incumbents in the same industry. ${ }^{43}$ Among the small number of

\footnotetext{
${ }^{41}$ No entry would then be observed in the theoretical model since entry is optimal only when the entrant can take away market shares from the incumbent.

${ }^{42}$ See, for example, Caves (1998), Dunne et al. (1988), Disney et al. (2003a) and Geroski (1995).

${ }^{43}$ According to our ARD data, for example, the average plant size of domestic entrants is about 10 times smaller than that of foreign entrants in their industry and about 7 times smaller than that of incumbent plants that are at least 5 years old.
} 
innovative domestic entrants are many that are initially hampered by financial constraints and immaturity of their technologies such that they are unlikely to challenge incumbents during their first years after market entry. Thus, aggregate domestic firm entry rates that do not exploit detailed firm information to separate between different types of domestic entrants pick up entry behind the technological frontier and insignificant effects on subsequent incumbent performance are reasonable.

\subsubsection{Resource reallocation and knowledge spillovers}

Our analysis so far contributes to a better understanding of the heterogeneity of entry effects on incumbent innovation and productivity growth across different industries. There are, however, other mechanisms whereby entry induces economic growth, that are not explored in this paper. The most important one is reallocation of productive inputs and outputs. High productivity entrants may induce the replacement of low productivity firms and thus increase productivity measured on an aggregated level. Empirical support for the importance of this mechanism is provided by Olley and Pakes (1996), Pavcnik (2002) and others. The dynamic industry model with heterogeneous firms by Melitz (2003) provides a theoretical analysis of reallocative effects triggered by opening up industries to international trade. In contrast to what we do, within-firm productivity is assumed to be constant in that paper and innovation incentives of incumbent firms are not considered. Bernard et al. (2003) consider reallocation of resources, plant turnover and measured productivity changes of incumbents caused by changing prices or by mark-up changes in an imperfect competition framework. They do not analyze effects of policy changes on within-firm incentives of incumbents, especially not heterogenous within-firm reactions. While we do not consider the within-industry reallocation effects these papers focus on we investigate in detail how entry effects within-firm changes of innovation incentives and productivity growth, and does so differently in industries at different distance to the industry-specific technological frontier.

Finally, we want to discuss the extent to which alternative theoretical explanations are also consistent with the pattern of empirical results reported above. Potential candidates 
are theories that focus on the role of knowledge spillovers instead of innovation incentives. Consider the widely established idea that firms and sectors further from the frontier should benefit most from knowledge spillovers, since the scope for learning is highest there. ${ }^{44}$ This suggests positive coefficients on the linear distance to frontier terms, as well as on the interactions with entry. We find, however, a different pattern, namely negative interaction effects and positive level effects of the distance to frontier measure (see sections 5.1 and 5.2 and tables 1 to 3$)$.

Our theoretical model generates predictions that are in line with both our empirical results. In section 2 we established the prediction of a negative interaction effect - innovation and productivity growth of incumbents in sectors close to the technological frontier react more positively to entry threat than in sectors further below the frontier. Now we show that if there is no threat of entry then the expected incumbent performance in a sector would be greater the further the sector is from the frontier (i.e. the level effect of the distance to the frontier would be positive). Assume for a moment that $p_{1}=p_{2}=0$. Then the innovation rates in the different types of sectors become:

$$
z_{1}=(\delta / c)(\gamma-1)<z_{2}=(\delta / c) \gamma<1
$$

from which we obtain: ${ }^{45}$

$$
g_{1}=z_{1}(\gamma-1)<g_{2}=z_{2}(\gamma-1)<g_{3}=(\gamma-1)
$$

Such a positive effect of the initial distance to frontier on expected productivity growth is to be expected in any model where sectors converge to the same expected growth rate. ${ }^{46}$

\footnotetext{
${ }^{44}$ Griffith et al. (2004) find empirical support for such consequences of general spillovers looking across a panel of OECD industries and countries. Griffith et al. (2002) find similar evidence at the establishment level in the UK.

${ }^{45}$ See footnote 13 for the derivation of $g_{3}$.

${ }^{46}$ In this particular model the economic reason for the result is twofold. First, expected growth in a sector three steps behind the frontier is higher than in a sector two steps behind because the former sector upgrades with probability one. Second, when there is no entry threat then a sector that is two steps behind is expected to grow faster than a sector just one step behind, because if the leader of the state- 2 sector does not innovate then its rival, who is three steps behind the frontier, will catch up with him and the leader will earn no
} 
Another idea prevalent in the existing literature on knowledge spillovers argues that firms in industries closer to the technological frontier have higher absorptive capacity and may benefit more from spillovers. If so, then firms in industries closer to the frontier should react stronger to general spillovers, as well as to knowledge transfers from entrants, than firms in industries farther behind the frontier. Our finding of negative and significant coefficients on the interaction terms is consistent with this. But the positive and significant coefficients for the linear distance to frontier terms are not in line with this explanation.

\section{Conclusions}

In this paper we investigate the substantial heterogeneity we see in the effects of entry on incumbent performance. We show first that the finding can be explained in the context of a simple multi-sector Schumpeterian growth model with entry. The main implication of the theoretical model is that a higher threat from technologically advanced entrants should encourage incumbent innovation in sectors that are initially close to the technological frontier (this we refer to as the "escape-entry effect"), whereas it may discourage incumbent innovation in sectors that are initially further behind the frontier (this we call the "discouragement effect" of entry). The intuition for these two effects is quite simple. In the former case, incumbent firms that are initially close to the frontier know they can escape entry by innovating; therefore a higher threat of entry will result in more intensive innovation activities aimed at escaping that threat. In the latter case, incumbents that are further behind the frontier have no hope to win against an entrant.

In the second part of the paper, we estimate the effects of entry allowing for effect heterogeneity. We use panel data from two entirely different sources - one containing information on incumbent TFP growth at the establishment level, the other containing information on patenting behavior of stock market listed firms. In both cases we control for confounding profits, whereas if the leader in a state-1 sector fails to innovate it will still remain one step ahead of its rival and hence will still earn positive profits; accordingly, the escape competition effect will give the leader in a state-2 sector a greater incentive to innovate than the leader of a state-1 sector. 
factors and for endogeneity of our main measure for technologically advanced entry, the foreign firm entry rate. We exploit exogenous variation across industries and time coming from product market interventions in the UK, including the introduction of the EU Single Market Program, decisions by the competition authorities and (de)regulations in the form of privatization decisions. Given our focus on heterogeneity of entry effects along the distance to frontier we also consider the endogeneity of distance measures and use US production and technology information as additional instruments. Our empirical analysis provides robust evidence and vindicates the theoretical implications of our growth model with entry. Most important, technologically advanced entry by foreign firms has a positive effect on innovation in sectors initially close to the frontier, but not on innovation in sectors initially further behind the frontier, and the effect of entry on productivity growth interacts negatively with the distance to frontier.

The results of our theoretical and empirical analysis can be linked to the policy debates on market (de)regulation, competition policy, large scale privatization, and trade liberalization. The main implication is that policies aiming at decreasing or removing entry barriers alone may not be sufficient to foster growth of incumbent firms in all sectors of an economy, even if such policies are found to be growth-enhancing on average. This, in turn, may suggest the introduction of complementary policies that facilitate, as well as the abolition of regulations that slow down, the reallocation of factors and resources towards sectors responding more positively to higher entry threat. 


\section{A Theory appendix}

\section{A.1 Endogenizing entry:}

Suppose that in an industry where the current leader is a type- $j$ firm, entrants at time $t$ need to pay the following entry fee to get an entry opportunity:

$$
F_{j t}=\lambda \bar{A}_{t}+\eta\left(\bar{A}_{t}-\bar{A}_{t-j}\right)
$$

where $j \in\{1,2,3\}$ and $\lambda$ is random and uniformly distributed between 0 and $\Lambda$. The term in $\eta$ reflects the additional cost that may arise for an entrant that brings up to frontier level a sector that was initially further below that frontier. In particular a high, positive $\eta$ will tend to make the equilibrium probability of entry into an industry a decreasing function of the industry's initial distance to frontier, whereas the opposite will hold if $\eta$ is small or equal to zero. Our main predictions turn out to be independent of whether $\eta$ is high or low.

The probability of entry in a type- $j$ sector is equal to the probability that the potential entrant pays the cost of entry, which in turn is the probability that the entrant's expected profit is greater than the entry fee $F_{j t}$.

In a type- 2 or type-3 sector, where the expected profit of an entrant is $\delta \bar{A}_{t}$ :

$$
p_{j}=\operatorname{pr}\left(\delta \bar{A}_{t}>F_{j t}\right)=\frac{\delta-\eta\left(1-1 / \gamma^{j}\right)}{\Lambda}, j \in\{2,3\} .
$$

In a type- 1 sector, the expected profit of an entrant is $\delta \bar{A}_{t}\left(1-z_{1}\right)$, where $z_{1}$ denotes the probability that a type- 1 incumbent leader innovates. In the main text we showed that this innovation probability itself depends upon the entry threat $p_{1}$, with

$$
z_{1}=\delta\left(p_{1}+\gamma-1\right) / c
$$

Thus, the probability $p_{1}$ must satisfy the fixed point equation:

$$
p_{1}=\operatorname{pr}\left(\delta \bar{A}_{t}\left(1-z_{1}\right)>F_{1 t}\right)=\frac{\delta-\delta^{2}(\gamma-1) / c-\eta(1-1 / \gamma)-\delta^{2} p_{1} / c}{\Lambda},
$$

or equivalently

$$
p_{1}=\frac{\delta-\delta^{2}(\gamma-1) / c-\eta(1-1 / \gamma)}{\Lambda+\delta^{2} / c}
$$

Therefore, all probabilities $p_{j}$ are decreasing in the common entry cost parameter $\Lambda$, namely $p_{J}^{\prime}(\Lambda)<0$ with $j \in\{1,2,3\}$.

\section{A.2 From entry threat to actual entry:}

The actual rate of entry in state- 2 sectors is 


$$
E_{2}=p_{2}(\Lambda)
$$

since potential entrants can never lose against a type-2 incumbent. Thus, entry threat and actual entry are the same, and therefore the comparative statics of innovation as a function of entry threat also leads to the unambiguous prediction of a negative correlation between innovation by type- 2 incumbents and actual entry in state- 2 sectors.

The actual entry rate in state- 1 sectors is

$$
E_{1}=p_{1}\left(1-z_{1}\right)
$$

so that the relationship between entry threat and actual entry in state- 1 sectors is a priori ambiguous: a higher entry threat induces more innovative activity by type- 1 incumbents in order to prevent entry, thereby counteracting the positive direct effect of entry threat on actual entry. However, the overall effect of entry threat on actual entry is positive, i.e. the effect of the entry cost parameter $\Lambda$ on actual entry is negative, when $\Lambda$ is not too small relative to the profit rate $\delta$ and the inverse of the $\mathrm{R} \& \mathrm{D}$ cost parameter $c$. We have

$$
\frac{\partial E_{1}}{\partial \Lambda}=\left(1-\frac{1}{c} \delta(\gamma-1)-2 \frac{1}{c} \delta p_{1}(\Lambda)\right) p_{1}^{\prime}(\Lambda)
$$

that is negative if and only if

$$
p_{1}(\Lambda)<\frac{1-\delta(\gamma-1) / c}{2 \delta / c}
$$

This holds if

$$
\Lambda>\delta^{2} / c
$$

\section{A.3 Steady-state distribution of sectors and average incumbent productivity growth}

Here we derive the steady-state fractions of all sectors $j$ and show that increased threat of entry has a positive effect on the average rate of productivity growth among active incumbent firms across all sectors of the economy for plausible values of the R\&D cost parameter $c$, frontier growth rate $\gamma$, entry cost parameter $\Lambda$ and the additional cost term $\eta$. The latter cost term arises for an entrant that brings up to frontier level a sector that was initially further below the frontier. Let $q_{j}$ denote the steady-state fraction of sectors in state $j$ and $\bar{A}_{t-j}$ the productivity in such sectors at the beginning of period $t$. In steady state, the net flow of sectors into each technological state $j \in\{1,2,3\}$ must equal the net flow out of that 
state. More formally, if $p_{j}$ denotes the entry threat into a type- $j$ sector, we have:

$$
\begin{aligned}
p_{2} q_{2}+p_{3} q_{3} & =\left(1-p_{1}\right)\left(1-z_{1}\right) q_{1} \\
\left(1-p_{1}\right)\left(1-z_{1}\right) q_{1} & =\left[p_{2}+\left(1-p_{2}\right)\left(1-z_{2}\right)\right] q_{2} \\
\left(1-p_{2}\right)\left(1-z_{2}\right) q_{2} & =p_{3} q_{3}
\end{aligned}
$$

plus the normalization

$$
q_{1}+q_{2}+q_{3}=1 \text {. }
$$

The left hand sides (right hand sides) of (15), (16) and (17) correspond to the net flows into (out of) states 1, 2 and 3, respectively. Only three of the above four equations are linearly independent, and thus can be used to solve for $q_{1}, q_{2}, q_{3}$. Then, if $g$ denotes the average productivity growth rate among active incumbent firms, we have:

$$
g=q_{1} g_{1}+q_{2} g_{2}+q_{3} g_{3} .
$$

We want to know how this growth rate is impacted by an increase in the entry cost parameter $\Lambda$ in the short run; that is, holding constant the probabilities $q_{i}$ defining the distribution of initial technology gaps.

We can establish the following:

Proposition: For $\eta, \gamma$ and $\Lambda$ sufficiently small, if $\delta<c$ then:

$$
\left.\frac{d g}{d \Lambda}\right|_{q=\text { const }} \equiv q_{1} \frac{d g_{1}}{d \Lambda}+q_{2} \frac{d g_{2}}{d \Lambda}+q_{3} \frac{d g_{3}}{d \Lambda}<0 .
$$

Proof: Since $g_{3}$ is independent of $\Lambda$, we have:

$$
\left.\frac{d g}{d \Lambda}\right|_{q=\text { const }}=q_{1} \frac{d g_{1}}{d \Lambda}+q_{2} \frac{d g_{2}}{d \Lambda}=(\gamma-1)\left(q_{1} \frac{d z_{1}}{d \Lambda}+q_{2} \frac{d z_{2}}{d \Lambda}\right),
$$

where we have made use of equation (5) in the text. Let

$$
u=\delta / c \text { and } \phi=\Lambda / \delta
$$

Now if we can prove the proposition for $\eta=0$, by continuity it will also hold for $\eta$ small. Thus, let us fix $\eta$ at zero. Using (10) and (12) we can then reexpress the probabilities of entry as:

$$
p_{1}(\phi)=\frac{1-u(\gamma-1)}{\phi+u} \text { and } p_{2}(\phi)=p_{3}(\phi)=1 / \phi .
$$

We can use (19) to reexpress the equilibrium innovation rates $z_{1}$ and $z_{2}$ respectively as:

$$
\left\{\begin{array}{l}
z_{1}(\phi)=u\left(p_{1}(\phi)+\gamma-1\right) \\
z_{2}(\phi)=u\left(1-p_{2}(\phi)\right) \gamma
\end{array}\right\}
$$


Next, using the steady-state equations $(15) \sim(18)$, we get:

$$
\left\{\begin{array}{l}
q_{1}(\phi)=\frac{p_{2}(\phi)}{p_{2}(\phi)+\left(1-p_{1}(\phi)\right)\left(1-z_{1}(\phi)\right)} \\
q_{2}(\phi)=\frac{q_{1}(\phi)\left(1-p_{1}(\phi)\right)\left(1-z_{1}(\phi)\right)}{p_{2}(\phi)+\left(1-p_{2}(\phi)\right)\left(1-z_{2}(\phi)\right)}
\end{array}\right\}
$$

So, we have:

$$
\begin{aligned}
\left.\frac{d g}{d \Lambda}\right|_{q=\text { const }} & =(\gamma-1)\left(q_{1}(\phi) \delta z_{1}^{\prime}(\phi)+q_{2}(\phi) \delta z_{2}^{\prime}(\phi)\right) \\
& \sim\left(z_{1}^{\prime}(\phi)+\frac{q_{2}(\phi)}{q_{1}(\phi)} z_{2}^{\prime}(\phi)\right) \\
& \sim\left(p_{1}^{\prime}(\phi)-\frac{\left(1-p_{1}(\phi)\right)\left(1-z_{1}(\phi)\right)}{p_{2}(\phi)+\left(1-p_{2}(\phi)\right)\left(1-z_{2}(\phi)\right)} \gamma p_{2}^{\prime}(\phi)\right) \\
& =\left(-\frac{1-u(\gamma-1)}{(\phi+u)^{2}}+\frac{\left(1-p_{1}(\phi)\right)\left(1-z_{1}(\phi)\right)}{p_{2}(\phi)+\left(1-p_{2}(\phi)\right)\left(1-z_{2}(\phi)\right)} \gamma \frac{1}{\phi^{2}}\right)
\end{aligned}
$$

Clearly $\phi$ and $\gamma$ have a lower limit of unity. (If $\phi<1$ then $p_{2}=p_{3}>1$, which makes no sense.) As we approach the limiting case where $\phi=\gamma=1$ then, from $(19) \sim(21)$, we have:

$$
p_{1}(\phi) \rightarrow \frac{1}{1+u}, p_{2}(\phi) \rightarrow 1, z_{1}(\phi) \rightarrow \frac{u}{1+u} \text { and } z_{2}(\phi) \rightarrow 0
$$

Substituting these into the final expression above for $\left.\frac{d g}{d \Lambda}\right|_{q=c o n s t}$, we have in the limit:

$$
\left.\frac{d g}{d \Lambda}\right|_{q=\text { const }} \sim\left(-\frac{1-u}{(1+u)^{2}}\right)
$$

in which the right-hand side is negative when $\delta<c$ because then $u<1$. $\|$

\section{B Data appendix}

\section{B.1 Data sources}

Plant and establishment level data for the manufacturing sector come from the UK Office for National Statistics (ONS). Its Annual Respondents Database (ARD) contains the micro data underlying the UK Annual Census of Production. ${ }^{47}$ Annual data on industry classification, ownership and employment is available for the whole population of British plants and allows for the construction of entry measures. ${ }^{48}$ Extensive additional data on inputs and outputs is available for a random stratified sample of establishments selected

\footnotetext{
${ }^{47}$ For recent years, the database is named Annual Business Inquiry (ABI). See Barnes and Martin (2002), Griffith (1999) and Oulton (1997) for further information.

${ }^{48}$ Before calculating entry measures we cleaned and checked the plant population data for 1973-1995, thereby reducing the number of observations by about 10 percent.
} 
for a detailed annual survey. ${ }^{49}$ The ARD survey is conducted under the 1947 Statistical Trade Act and survey response is mandatory. Establishments with more than 100 employees are all selected, as well as a stratified random sample of smaller units. ${ }^{50}$ The plant and establishment data is supplemented with ownership information that is yearly updated from Dun \& Bradstreet's "Who own's Whom". Owner nationality indicates for all plants and establishments of a firm the nationality of the largest shareholder controlling at least 20 percent of that firm. We weight observations by employment and the inverse of their sampling probability.

We restricted our sample to observations on incumbent establishments under domestic ownership that are (i) at least 5 years old or (ii) had at least once between 1986 and 1993 more than 100 employees. ${ }^{51}$ We excluded from the sample all establishments not yet producing or under public ownership, observations before 1987 and after 1993, trimmed the sample with respect to key variables, ${ }^{52}$ dropped establishments observed for less than three consecutive years and do not allow for reappearance of establishments. The resulting sample contains 23,802 observations on 4,947 domestic incumbent establishments. Descriptive statistics are provided in Table B.4.

Firm level data on patenting activity is taken from the NBER/Case Western Patent database that covers over two million patents granted by the US Patent Office since 1901. The patent data is linked to annual DataStream accounting data since 1968 for a sample of firms listed on the London Stock Exchange (LSE) in 1985. ${ }^{53}$ All firms in the database are considered to be incumbent since firms listed at the LSE are typically reasonably old and large. For estimation purposes we purged the raw database from non-manufacturing firms and observations before 1987 and after 1993, trimmed the sample with respect to key variables, ${ }^{54}$ and excluded firms with less than three consecutive observations considering accounting periods of less (more) than 300 (400) days as series breaks. This leaves us with

\footnotetext{
${ }^{49}$ About 76 percent of all sampled establishments between 1980 and 1993 are single plants, all others represent groups of on average 1.6 plants operating in the same 4-digit industry and owned by the same firm.

${ }^{50}$ The sample selected for the survey accounts for about 90 percent of annual total British manufacturing employment according to Oulton (1997).

${ }^{51}$ Empirical results were robust when experimenting with stricter definitions, for example, when imposing (i) and (ii).

${ }^{52}$ We dropped observations with missing key variables (output, value added, intermediate inputs, employment, capital stock), observations where absolute growth in key variables was over 150 percent, and observations with extreme values below (above) the 1- (99-)percent percentiles of the productivity growth, entry rate or distance to frontier distributions.

${ }^{53}$ The sample covers 415 firms listed at LSE in 1985 with names starting with A-L and all top 100 R\&D spenders not already included. Subsidiaries of these firms were identified using "Who owns Whom" by Dun and Bradstreet in 1985 and all entities were matched by name to the NBER/Case Western Patent database. See Bloom and Van Reenen (2002) for further information.

${ }^{54}$ We dropped observations with missing values of sales, capital and employment, observations where absolute growth of these key variables exceeded 150 percent, and observations with extreme values of the entry rate or distance to frontier distributions.
} 
an estimation sample of 1,085 observations on 176 firms described in greater detail in Table B.4.

Industry level data on US 4-digit industries come from the NBER manufacturing productivity (MP) database and for UK industries it is aggregated from the ARD database. ${ }^{55}$ When calculating the distance to frontier measures for the productivity growth (patent count) models we matched UK 4-digit (3-digit) industries to the corresponding US 4-digit (3-digit) industries. For the matching we used the US SIC 1987 and the UK SIC 1980 industry code. ${ }^{56}$ Further 2-digit industry level data on import penetration in UK and US R\&D intensity are taken from the OECD STAN database.

\section{B.2 Definitions of variables}

Productivity growth: When calculating TFP growth we apply a standard factor share approach, use a superlative index derived from a flexible translog specification of the production technology (Caves et al. 1982a, b), and disaggregated ARD survey data on establishment output and inputs:

$$
\triangle T F P_{i t}=\triangle \ln Y_{i t}-\sum_{z=1}^{Z} \tilde{\alpha}_{i t}^{z} \triangle \ln x_{i t}^{z},
$$

where $Y$ denotes output, $Z$ the number of factors of production, and $x_{i t}^{z}$ the quantity used of factor $z$ in establishment $i$ at time $t$. We consider four factors of production in $Z$ : skilled labor (administratives, technical and clerical workers), unskilled labor (operatives), the stock of physical capital, and intermediate inputs.

Factor shares $\tilde{\alpha}_{i t}^{z}$ are defined as $\tilde{\alpha}_{i t}^{z}=\left(\alpha_{i t}^{z}+\alpha_{i t-1}^{z}\right) / 2$ with $\alpha_{i t}^{z}$ denoting the cost of factor $z$ relative to total output value in establishment $i$ at time $t$. Since observed factor shares $\alpha_{i t}^{z}$ can be noisy and may exceed one we apply a smoothing procedure proposed by Harrigan (1997). Assuming a translog production technology, constant returns to scale (CRS), and standard market-clearing conditions, $\alpha_{i t}^{z}$ can be expressed as follows:

$$
\alpha_{i t}^{z}=\psi_{i}+\varphi_{j t}+\sum_{z=2}^{Z} \omega_{j}^{z} \ln \left(\frac{x_{i t}^{z}}{x_{i t}^{1}}\right),
$$

where $\psi_{i}$ is a establishment-specific constant, $\varphi_{j t}$ an industry-time-specific constant and where we normalize relative to production factor 1 to impose CRS. ${ }^{57}$ If observed factor shares deviate from the left-hand side of this equation by an i.i.d. measurement error term,

\footnotetext{
${ }^{55}$ See Bartelsman and Gray (1996) and Griffith (1999) for variable definitions in both databases.

${ }^{56}$ Of all 205 4-digit industries in the ARD database 146 could be linked exclusively to one or several US 4-digit industries. 50 of the remaining industries could be successfully linked to US industries after having formed pairs and three larger groups of 4-digit industries. Nine UK industries could not be linked to an industry in the US manufacturing sector.

${ }^{57}$ See Caves et al. (1982b) and Harrigan (1997).
} 
then its parameters can be estimated by running separate fixed effects panel data regressions for each 4-digit industry $j$. The fitted values from (23) are then used as factor shares in the calculation of $(22)$.

For our main TFP growth measure we impose constant returns to scale $\left(\sum_{z} \tilde{\alpha}_{i t}^{z}=1\right)$. Alternatively, we follow Klette (1999) and use estimated price markups above costs to calculate a second TFP growth measure that does not depend on the assumption of perfect product market competition. ${ }^{58}$

Number of patents: The dependent variable in the patent count models is the annual number of patents a firm listed at the LSE took out at the U. S. Patent Office.

Import penetration: We calculate the ratio of the annual value of imports over domestic output using 2-digit industry level data from the OECD STAN database.

Competition: For the productivity growth (patent count) models we use a 4-digit (3digit) industry level competition index that is defined as 1 minus a market share-weighted average of the Lerner index across all establishments in the industry. The measure takes values between 0 and 1 and a value of 1 indicates perfect competition. The establishmentspecific Lerner index is proxied by annual output minus labor, intermediate good and capital costs divided by output using ARD data..$^{59}$

Pre-sample patent variable: Pre-sample patent information for firms listed at LSE is used to construct a measure of the firm-specific patent stock built up between 1968 and the beginning of the first year the firm is in our estimation sample, i.e. 1987 in most cases. We apply the perpetual inventory method and calculate the stock measure as the sum of all presample patents depreciated to the end of the pre-sample period using an annual knowledge depreciation rate of 30 percent. $^{60}$ In addition to the stock measure, we constructed an indicator of pre-sample patenting activity equal to one if the firm ever patented in the presample period.

For the definition of entry and distance to frontier measures see section 4 in the main text.

[Tables B.1-B.4 here]

\footnotetext{
${ }^{58}$ Empirical results when using this measure and results when using a standard labor productivity measure are reported in sub-section 5.3.1.

${ }^{59}$ Experimenting with an unweighted average or different weights had only negligible effects on the estimated effects of entry, distance to frontier and interaction terms. Using a market share measure instead of a rent-based competition measure also gave similar results.

${ }^{60}$ We found our empirical results to be insensitive to the chosen depreciation rate when experimenting with other rates between 15 and 45 percent.
} 


\section{References}

Aghion, Philippe; Bloom, Nicholas; Blundell, Richard; Griffith, Rachel and Howitt, Peter. "Competition and Innovation: An Inverted U Relationship." Quarterly Journal of Economics, May 2005a, pp. 701-728.

Aghion, Philippe; Blundell, Richard; Griffith, Rachel; Howitt, Peter and Prantl, Susanne. "Entry and Productivity Growth: Evidence From Microlevel Panel Data." Journal of the European Economic Association, April-May 2004 2(2-3), pp. 265-276.

Aghion, Philippe; Burgess, Robin; Redding, Stephen and Fabrizio Zilibotti. "Entry Liberalization and Inequality in Industrial Performance." Journal of the European Economic Association, April-May 2005b, 3(2-3), pp. 291-302.

Aghion, Philippe and Rachel Griffith. Competition and Growth: Reconciling Theory and Evidence, Cambridge, MA: MIT Press, 2005

Aghion, Philippe; Harris, Christopher; Howitt, Peter and Vickers, John. "Competition, Imitation and Growth with Step-by Step Innovation." Review of Economic Studies, July 2001, 68, pp. 467-492.

Aghion, Philippe; Harris, Christopher and Vickers, John. "Competition and Growth with Step-by-step Innovation: An Example." European Economic Review, April 1997, 41, pp. 771-782.

Aitken, Brian J. and Harrison, Ann E. "Do Domestic Firms Benefit from Direct Foreign Investment? Evidence from Venezuela." American Economic Review, June 1999, 89(3), pp. 605-618.

Barnes, Matthew and Martin, Ralf. "Business Data Linking: An Introduction." Economic Trends, April 2002, 581, pp. 34-41.

Barro, Robert J. and Sali-i-Martin, Xavier. Economic Growth, 2nd ed., Cambridge, MA: MIT Press, 2004.

Bartelsman, Eric J. and Gray, Wayne. "The NBER Manufacturing Productivity Database." National Bureau of Economic Research (Cambridge, MA) Technical Working Paper No. 205, October 1996.

Bernard, Andrew B.; Eaton, Jonathan; Jensen, J. Bradford and Kortum, Samuel. "Plants and Productivity in International Trade." American Economic Review, September 2003, 93(4), pp. 1268-1290.

Berry, Steven. "Estimation of a Model of Entry in the Airline Industry." Econometrica, Vol. 60, No. 4, July 1992, 889-917.

Berry, Steven and Ariel Pakes. "Empirical Models of Entry and Market Structure.", prepared for: Handbook of Industrial Organization, vol. III, by R. H. Porter and M. Armstrong, Amsterdam: North Holland, 2003.

Bertrand, Marianne and Kramarz, Francis. "Does Entry Regulation Hinder Job Creation? Evidence from the French Retail Industry." Quarterly Journal of Economics, November 2002, 
117(4), pp. 1369-1413.

Bertschek, Irene. "Product and Process Innovation as a Response to Increasing Imports and Foreign Direct Investment." Journal of Industrial Economics, December 1995, 43(4), pp. 341-357.

Bloom, Nicholas and Van Reenen, John. "Real Options, Patents, Productivity and Market Value: Evidence from a Panel of British Firms." Economic Journal, March 2002, 112, pp. C97-C116.

Blundell, Richard; Griffith, Rachel and Van Reenen, John. "Market Share, Market Value and Innovation in a Panel of British Manufacturing Firms." Review of Economic Studies, July 1999, 66, pp. 529-554.

Blundell, Richard and Powell, James. "Endogeneity in Nonparametric and Semiparametric Regression Models." In Dewatripont, Mathias; Hansen, Lars Peter and Turnovsky, Stephen J. (eds.). Advances in Economics and Econometrics, Vol. II, Econometric Society Monograph Series, Eighth World Congress, Cambridge, UK: Cambridge University Press, April 2003.

Bresnahan, Timothy F. and Reiss, Peter C. "Entry in Monopoly Markets." Review of Economic Studies, October 1990, 57, pp. 531-553.

Bresnahan, Timothy F. and Reiss, Peter C. "Entry and Competition in Concentrated Markets." Journal of Political Economy, October 1991, 99(5), pp. 977-1009.

Caves, Richard. "Industrial Organization and New Findings on the Turnover and Mobility of Firms." Journal of Economic Literature, December 1998, 36, pp. 1947-1982.

Caves, Douglas W.; Christensen, Laurits R. and Diewert, W. Erwin. "Multilateral Comparisons of Output, Input, and Productivity Using Superlative Index Numbers." Economic Journal, March 1982a, 92, pp. 73-86.

Caves, Douglas W.; Christensen, Laurits R. and Diewert, W. Erwin. "The Economic Theory of Index Numbers and the Measurement of Input, Output, and Productivity." Econometrica, November 1982b, 50(6), pp. 1393-1414.

Clarke, Roger; Davies, Stephen and Driffield, Nigel. Monopoly Policy in the UK. Cheltenham, UK: Edward Elgar, 1998.

Davies, Stephen W.; Driffield, Nigel L. and Clarke, Roger. "Monopoly in the UK: What Determines Whether the MMC Finds Against the Investigated Firms?" Journal of Industrial Economics, September 1999, 47(3), pp. 263-283.

Disney, Richard; Haskel, Jonathan and Heden, Ylva. "Entry, Exit and Establishment Survival in UK Manufacturing." Journal of Industrial Economics, March 2003a, 51(1), pp. 91-112.

Disney, Richard; Haskel, Jonathan and Heden, Ylva. "Restructuring and Productivity Growth in UK Manufacturing." Economic Journal, July 2003b, 113 (489), pp. 666-694.

Djankov, Simeon; La Porta, Rafael; Lopez de Silanes, Florencio and Shleifer, Andrei. "The Regulation of Entry." Quarterly Journal of Economics, February 2002, 117(1), pp. 1-37. 
Dunne, Timothy; Roberts, Mark J. and Samuelson, Larry. "Patterns of Firm Entry and Exit in U.S. Manufacturing Industries." RAND Journal of Economics, Winter 1988, 19(4), pp. $495-515$.

European Commission. "Completing the Internal Market." White Paper from the Commission to the European Council (Milan, 28-29 June 1985), COM (85) 310, 14 June 1985.

Fudenberg, Drew and Tirole, Jean. "The Fat Cat Effect, the Puppy Dog Ploy and the Lean and Hungry Look.", American Economic Review, Papers and Proceedings, May 1984, 74(2), pp. 361-366.

Geroski, Paul. "What do we know about entry?" International Journal of Industrial Organization, 13 (1995) 421-440

Gilbert, Richard J. and Newbery, David.M.G. "Preemptive Patenting and the Persistence of Monopoly." American Economic Review, June 1982, 72(3), pp. 514-526.

Griffith, Rachel. "Using the ARD Establishment Level Data to Look at Foreign Ownership and Productivity in the United Kingdom." Economic Journal, June 1999, 109, pp. F416F442.

Griffith, Rachel; Redding, Stephen and Van Reenen, John. "Mapping the Two Faces of R\&D: Productivity Growth in a Panel of OECD Industries.", Review of Economics and Statistics, November 2004, 86(4), pp. 883-895.

Griffith, Rachel; Redding, Stephen and Simpson, Helen. "Productivity Convergence and Foreign Ownership at the Establishment Level.", CEPR Discussion Paper No. 3765, February 2002.

Haskel, Jonathan; Pereira, Sonja and Slaughter, Matthew. "Does Inward Foreign Direct Investment Boost the Productivity of Domestic Firms?" National Bureau of Economic Research (Cambridge, MA), Working Paper No. 8724, January 2002

Harrigan, James. "Technology, Factor Supplies, and International Specialization: Estimating the Neoclassical Model." American Economic Review, September 1997, 87(4), pp. 475-494.

Javorcik, Beata Smarzynska. "Does Foreign Direct Investment Increase the Productivity of Domestic Firms? In Search of Spillovers Through Backward Linkages." American Economic Review, June 2004, 94(3), pp. 605-627.

Keller, Wolfgang and Yeaple, Stephen R. "Multinational Enterprises, International Trade, and Productivity Growth: Firm-Level Evidence from the United States." Mimeo, University of Texas and University of Pennsylvania, November 2004.

Klette, Tor Jakob. "Market Power, Scale Economies and Productivity: Estimates from a Panel of Establishment Data." Journal of Industrial Economics, December 1999, 47(4), pp.451-476.

Klette, Tor Jakob and Zvi Griliches. "The Inconsistency of Common Scale Estimators when Output Prices are Unobserved and Endogeneouy." Journal of Applied Econometrics, JulyAugust 1996, 11(4), pp.343-361.

Laffont, Jean-Jacques and Tirole, Jean. A Theory of Incentives in Procurement and Regu- 
lation. Cambridge, MA: MIT Press, 1993.

Mazzeo, Michael J. "Product Choice and Oligopoly Market Structure.", RAND Journal of Economics, 33(2), pp. 221-242.

Mayes, David and Hart, Peter. The Single Market Programme as a Stimulus to Change: Comparisons between Britain and Germany. Cambridge, UK: Cambridge University Press, 1994.

Melitz, Marc J. "The Impact of Trade on Intra-Industry Reallocations and Aggregate Industry Productivity." Econometrica, November 2003, 71(6), pp. 1695-1725.

Monopoly and Merger Commission. Various Reports. http://www.mmc.gov.uk.

Moulton, Brent R. "An Illustration of a Pitfall in Estimating the Effects of Aggregate Variables on Micro Units.", Review of Economics and Statistics, May 1990, 72(2), pp. 334-338.

Nickell, Stephen J. "Competition and Corporate Performance", Journal of Political Economy, August 1996, 104(4), pp. 724-746.

Nicoletti, Guiseppe and Scarpetta, Stefano. "Regulation, productivity and growth: OECD evidence." Economic Policy, April 2004, pp. 9-72.

Oulton, Nicholas. "The ABI Respondents Database: A New Resource for Industrial Economics Research.", Economic Trends, November 1997, 528, pp. 46-57.

Olley, G. Steven and Pakes, Ariel. "The Dynamics of Productivity in the Telecommunications Equipment Industry." Econometrica, November 1996, 64(6), pp. 1263-1297.

Parker, David. "The UK's Privatisation Experiment: The Passage of Time Permits a Sober Assessment.", CESIFO Working Paper No. 1126, February 2004.

Pavcnik, Nina. "Trade Liberalization, Exit, and Productivity Improvements: Evidence from Chilean Plants." Review of Economic Studies, January 2002, 69(1), pp. 245-276.

PriceWaterhouseCoopers. "Experience of Privatization in the UK." PwC Briefing Note, 1998, http://www.pwcglobal.com/uk/eng/about/svcs/pfp/pwc_priv_uk.pdf.

Seim, Katja. "An Empirical Model of Firm Entry with Endogeneous Product-Type Choices." Mimeo, Stanford Graduate School of Business, September 2004.

Tirole, Jean. The Theory of Industrial Organization. Cambridge, MA: MIT Press, 1988.

Wooldridge, Jeffrey M. Econometric Analysis of Cross Section and Panel Data, Cambridge, MA: MIT Press, 2002.

Zilibotti, Fabrizio; Acemoglu, Daron and Philippe Aghion. "Distance to Frontier, Selection, and Economic Growth.", Journal of the European Economic Association, 2006, forthcoming. 


\section{Figure 1: Entry effects near and far from the technological frontier}

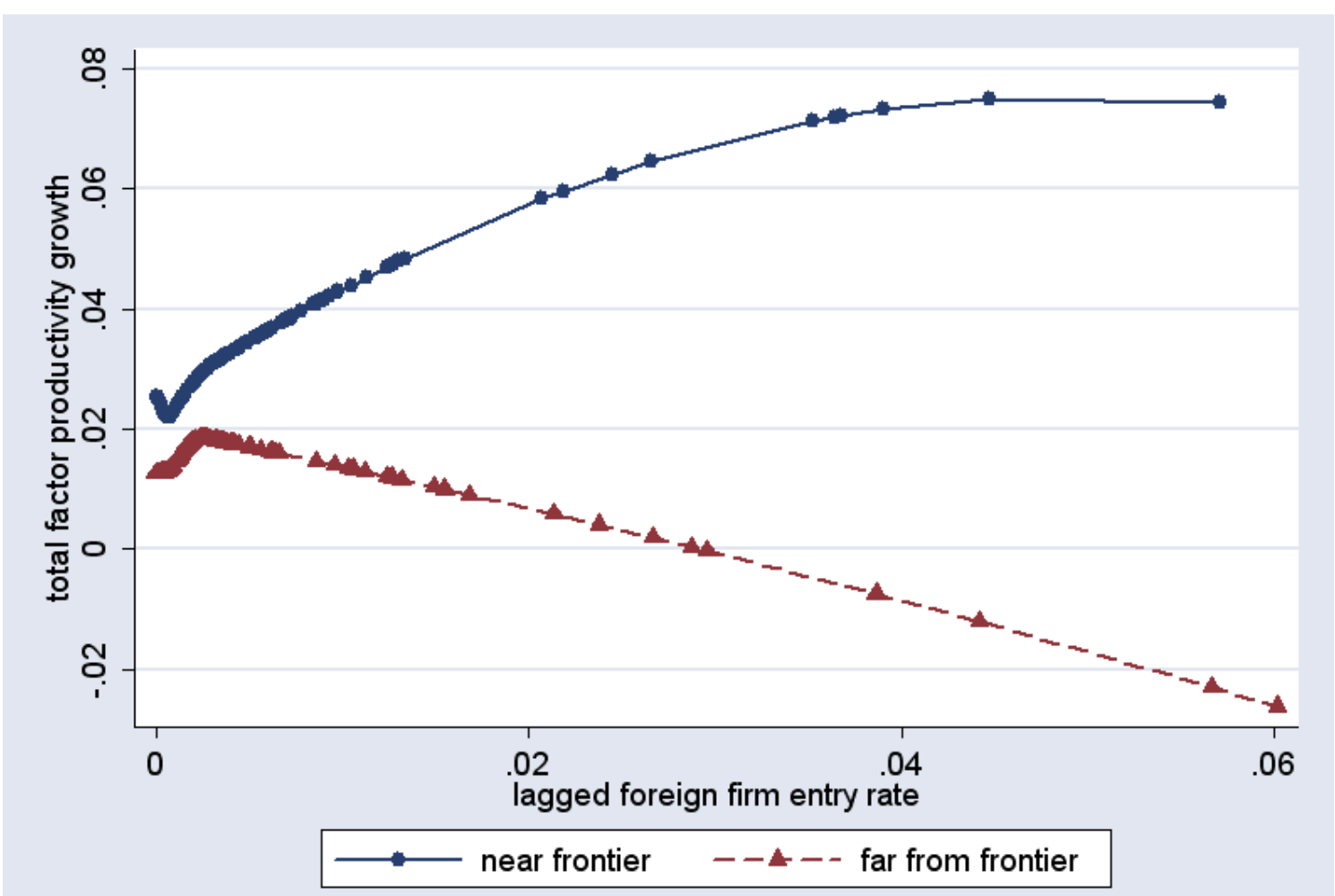

Notes: The figure plots spline estimates of the relation between the foreign firm entry rate and subsequent TFP growth of domestic incumbent establishments in UK 4-digit industries, 1987 to 1993. Each dot represents the average TFP growth estimate for establishments in one industry-year cell. Three spline points are chosen such that all establishment observations in industry-year cells with non-zero entry are grouped into four equally sized classes. The distance to technological frontier is a relative labor productivity measure relating 4-digit US to UK industries. The top (blue) curve is for establishments in industry-year cells near the technological frontier, i.e. less or equally distant to the frontier as the sample median of the distance. The bottom (red) curve is for establishments further behind the technological frontier, i.e. more distant to the frontier than the sample median.

Source: Authors' calculations using ONS and other data. All statistical results remain Crown Copyright. 
Table 1: TFP growth models

Dependent variable:

growth of total factor productivity ${ }_{\mathrm{ijt}}$

\begin{tabular}{|c|c|c|c|c|c|}
\hline Independent variables: & (1) & (2) & (3) & (4) & (5) \\
\hline foreign entry $_{\mathrm{jt}-1} *$ distance $_{\mathrm{jt}-1}$ & & & & $\begin{array}{l}-4.422^{* * *} \\
(1.386)\end{array}$ & $\begin{array}{l}-9.316^{* * *} \\
(2.226)\end{array}$ \\
\hline foreign entry $\mathrm{jt}_{\mathrm{j}-1}$ & $\begin{array}{l}0.796^{* *} \\
(0.382)\end{array}$ & $\begin{array}{c}0.737^{* *} \\
(0.375)\end{array}$ & $\begin{array}{l}2.971^{* * *} \\
(0.327)\end{array}$ & $\begin{array}{l}1.821^{* * *} \\
(0.468)\end{array}$ & $\begin{array}{l}4.657^{* * *} \\
(0.385)\end{array}$ \\
\hline distance to frontier ${ }_{\mathrm{jt}-1}$ & & $\begin{array}{l}0.079^{* * *} \\
(0.027)\end{array}$ & $\begin{array}{l}0.073^{* *} \\
(0.026)\end{array}$ & $\begin{array}{l}0.089^{* * *} \\
(0.025)\end{array}$ & $\begin{array}{l}0.082^{* *} \\
(0.039)\end{array}$ \\
\hline import penetration $_{\mathrm{jt}-1}$ & & $\begin{array}{c}0.079^{* *} \\
(0.033)\end{array}$ & $\begin{array}{l}0.077^{* *} \\
(0.035)\end{array}$ & $\begin{array}{l}0.080^{* *} \\
(0.033)\end{array}$ & $\begin{array}{l}0.080^{* *} \\
(0.034)\end{array}$ \\
\hline competition $_{\mathrm{jt}-1}$ & & $\begin{array}{c}0.127^{*} \\
(0.071)\end{array}$ & $\begin{array}{c}0.140^{* *} \\
(0.058)\end{array}$ & $\begin{array}{c}0.117^{*} \\
(0.065)\end{array}$ & $\begin{array}{l}0.121^{* *} \\
(0.049)\end{array}$ \\
\hline
\end{tabular}

F, exogeneity of...

entry

entry, distance \& interaction

26. $90(1)^{* * *}$

$\chi^{2}$, overidentification

13. $73(10)$

17. $14(3)^{* * *}$

First stage equations:

interaction: $\mathrm{R}^{2}$

$\mathrm{F}$, excluded

0.3069

instruments

entry: $\quad \mathrm{R}^{2}$

0.3038

2. $72(16)^{* * *}$

$\mathrm{R}^{2}$

5. $02(11)^{* * *}$

0.3047

$\mathrm{F}$, excluded

3. $44(16)^{* * *}$

distance: $\mathrm{R}^{2}$ instruments

0.9326

F, excluded

13. $61(16)^{* * *}$ instruments

\begin{tabular}{lccccc}
\hline year dummies & Yes & Yes & Yes & Yes & Yes \\
establishment fixed effects & Yes & Yes & Yes & Yes & Yes \\
number of observations & 23,802 & 23,802 & 23,802 & 23,802 & 23,802 \\
\hline \hline
\end{tabular}

Notes: The sample consists of 23,802 observations on domestic incumbent establishments between 1987 and 1993. Robust standard errors in brackets and italics are clustered by industry. *** $(* *, *)$ indicates significance at the $1(5,10)$-percent significance level. Observations are weighted by employment and the inverse of their sampling probability. For first stage test results degrees of freedom are in brackets. All regressions include a full set of year dummies and establishment fixed effects. The variable foreign entry is the lagged foreign firm entry rate, distance to frontier is the lagged relative labor productivity measure relating 4-digit US to UK industries, import penetration is lagged imports over domestic output, and competition is a lagged rent-based competition measure.

Source: Authors' calculations using ONS and other data. All statistical results remain Crown Copyright. 


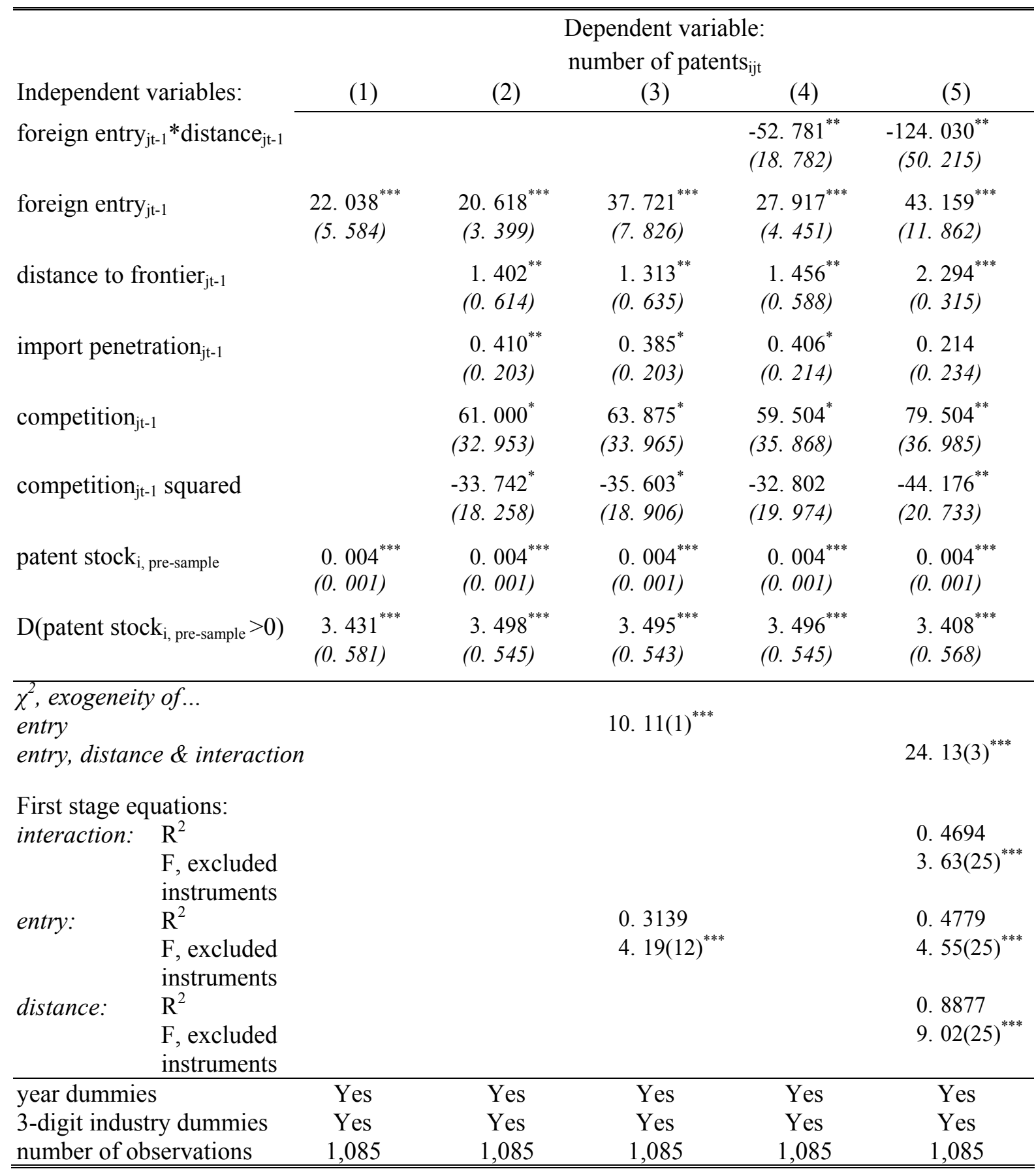

Notes: The sample consists of 1,085 observations on incumbent firms listed at the London stock exchange between 1987 and 1993. Robust standard errors in brackets and italics are clustered by industry. *** $(* *, *)$ indicates significance at the 1 $(5,10)$-percent significance level. For first stage test results degrees of freedom are in brackets. All regressions include a full set of year dummies, 3-digit industry dummies and patent stock variables to capture unobservable, time-invariant firm heterogeneity. The variable foreign entry is the lagged foreign firm entry rate, distance to frontier is the lagged relative labor productivity measure relating 3-digit US to UK industries, import penetration is lagged imports over domestic output, and competition is a lagged rentbased competition measure.

Source: Authors' calculations using ONS and other data. All statistical results remain Crown Copyright. 


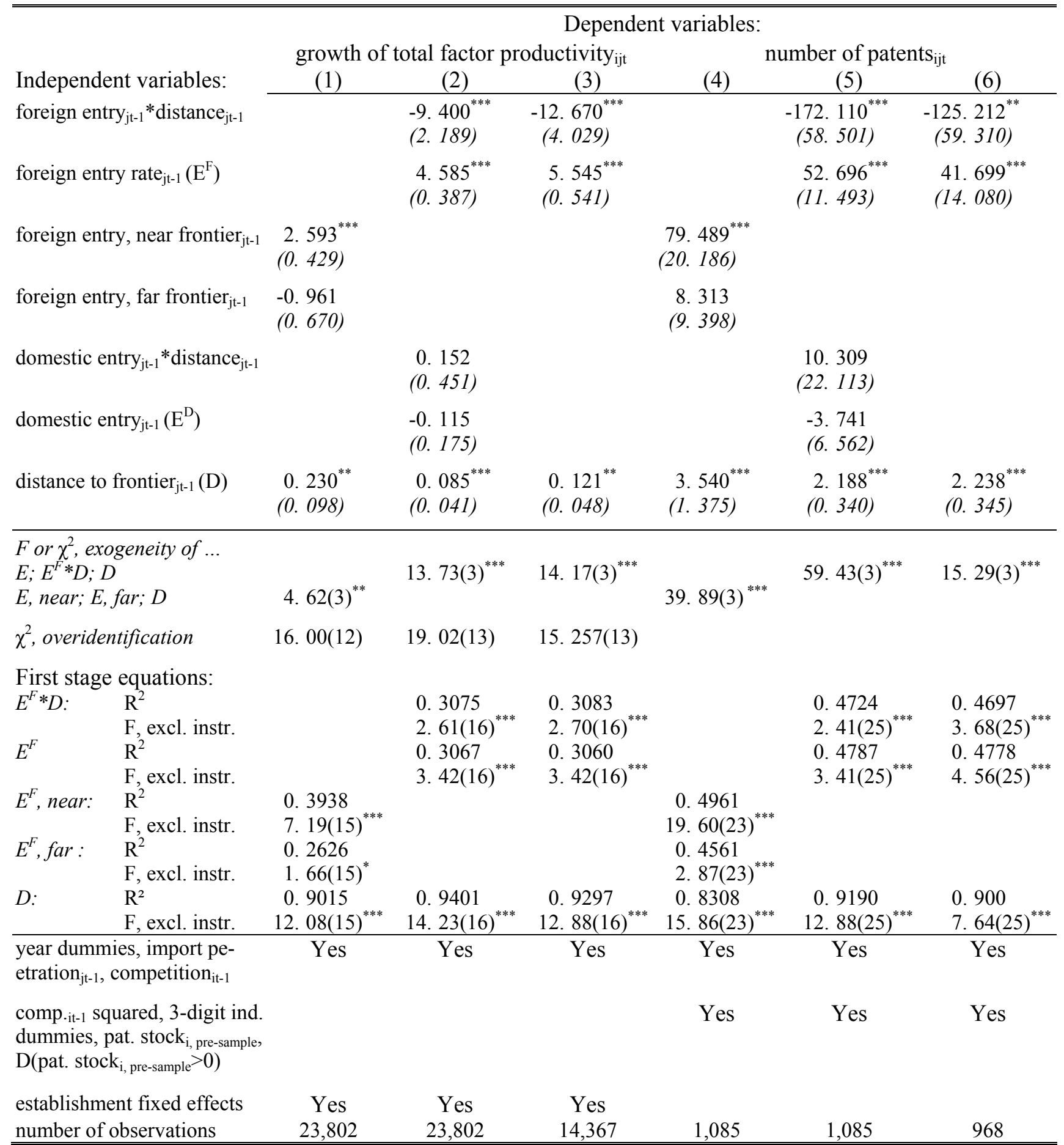

Notes: Robust standard errors in brackets and italics are clustered by industry. $* * *(* *, *)$ indicates significance at the 1 $(5,10)$-percent significance level. For first stage test results degrees of freedom are in brackets. All regressions include control variables for import penetration and competition, a full set of year dummies, establishment fixed effects or 3-digit industry dummies and patent stock variables to capture unobservable, time-invariant firm heterogeneity. For sample and variable description see the respective notes in Table 1 or 2 and main text.

Source: Authors' calculations using ONS and other data. All statistical results remain Crown Copyright. 
Table B.1: Product market policy interventions

EU Single Market Program (SMP) Year

The implementation of the EU SMP began in 1988 and 41 3-digit industries were ex 1988 ante expected to be strongly or moderately affected by it. The aims of the SMP were to bring down EU internal barriers to the free movement of goods, services, capital and labor by interventions like harmonizing product standards, indirect taxes and border controls, removing national requirements and other non-tariff barriers that enable firms to segment markets and limit competition, restricting public sector discrimination in favor of its own firms, and reducing capital as well as labor costs by permitting free flow across countries. ${ }^{1}$

\section{Monopoly and merger cases}

Year

Industry

code

The UK Competition Authority has responsibility for undertaking case-by-case investigations of potential mergers or potential monopoly situations in order to determine whether the merger or actions of firms in the industry are, or can be expected, to operate against the public interest by distorting competition, preventing entry, increasing prices or reducing consumers' choice. Where the Commissioners conclude that this is the case they can recommend remedial interventions such as prohibitions or divestments. We use information on cases where remedial actions were recommended and undertaken. ${ }^{2}$

Opium derivatives

Advertising in rambling magazines

Roof trusses and connector plates

Medical and surgical equipment

Beer and brewing industry

1988, 1990,

Defense equipment, electronics industry, telecommunications 1992

Sewing thread and textile industry

Tires

Fertilizers

Razors and shaving equipment

Sugar

Carbonated drinks and soft drinks

Matches, cigarette lighters, smokers requisites

Wool, wool scouring, textile industry

Shoe polish

Dairy products and milk

Cross media promotion of publications

\footnotetext{
${ }^{1}$ See the European Commission's White Paper (1985) and Mayes and Hart (1994) for further details on EU SMP. The list of 413 -digit industries that were ex ante expected to be affected by the introduction of the EU Single Market can be found in Mayes and Hart (1994, p.53).

${ }^{2}$ See http://www.competition-commission.gov.uk/ for published case reports. Davies et al. (1999) and Clarke et al. (1998) provide further analyses of these cases.
} 
The Thatcher government embarked on a large scale privatization program in the early 1980s which led to the sale of a substantial portion of government owned assets. In most cases, these privatization decisions resulted in opening up these and related markets to entry by new firms. ${ }^{3}$

Ordnance, small arms and ammunition: Royal Ordnance

Motor vehicles and engines: Leyland Bus, Leyland Truck, Freight Rover, Rover

Table B.2: Large 4-digit industries by distance to technological frontier

\begin{tabular}{lrr}
\hline \hline SIC 80 code & Industry description & $\begin{array}{l}\text { US-UK relative labor } \\
\text { productivity, 1984-1986 }\end{array}$
\end{tabular}

Large industries close to the frontier ( $\leq$ median distance to frontier)

\begin{tabular}{llr}
\hline 4310 & woolen and worsted industry & 0.084 \\
4671 & wooden and upholstered furniture & 0.049 \\
4510 & Footwear & 0.111 \\
4725 & packaging products of boards & 0.118 \\
4751 & printing and publishing of newspapers & 0.214 \\
4536 & woman's and girl's light outerwear & 0.290 \\
4363 & hosiery and other weft knitted goods and fabrics & 0.316 \\
3443 & radio and electronic capital goods & 0.362 \\
3284 & refrigerating, heating and ventilating equipment & 0.414 \\
2489 & ceramic goods & 0.426
\end{tabular}

Large industries further behind the frontier ( $>$ median distance to frontier)

\begin{tabular}{llr}
\hline 3420 & basic electrical equipment & 0.517 \\
3640 & aerospace equipment manufacturing and repairing & 0.519 \\
2570 & pharmaceutical products & 0.585 \\
4196 & bread and flour confectionery & 0.664 \\
4197 & biscuits and crisp-bread & 0.664 \\
2551 & Paints, varnishes and painters' filings & 0.691 \\
4270 & brewing and malting & 0.779 \\
4122 & bacon curing and meat processing & 0.893 \\
3460 & domestic-type electric appliances & 0.894 \\
3530 & motor vehicle parts & 0.945 \\
\hline \hline
\end{tabular}

Notes: The industries listed here are the largest UK 4-digit industries in the group of industries close to the technological frontier and further behind the frontier. Industry size is measured by employment and the distance by labor productivity in 4-digit US relative to UK industries between 1984 and 1986. Calculations are based on data for all 1235 industry-year cells in the estimation sample for productivity growth models.

Source: Authors' calculations using ONS and other data. All statistical results remain Crown Copyright.

\footnotetext{
${ }^{3}$ See PriceWaterhouseCoopers (1998) and Parker (2004) for more information.
} 
Table B.3: Entry and distance to the technological frontier

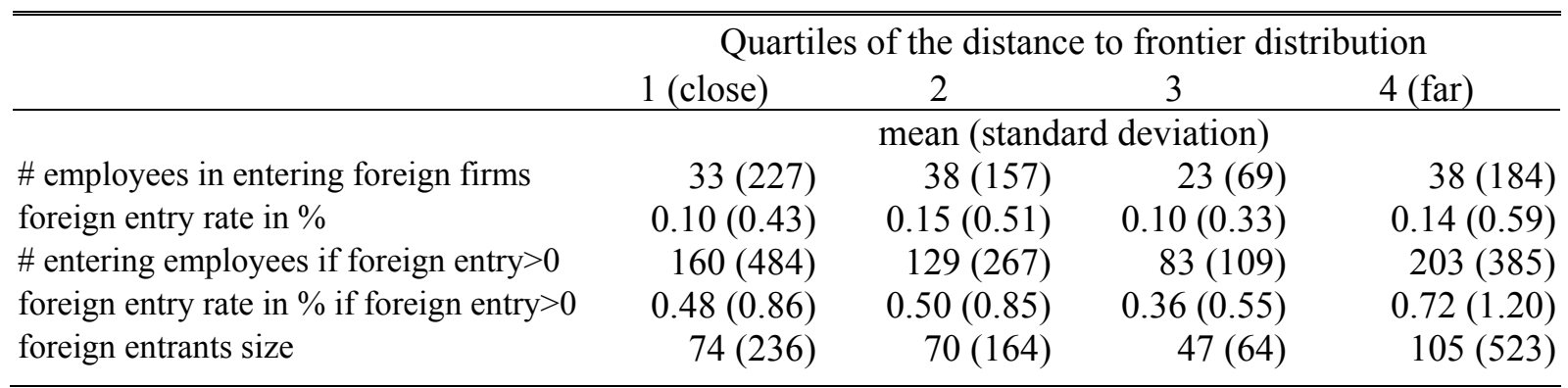

Notes: The table describes how foreign firm entry between 1986 and 1992 varies with the distance of UK 4-digit industries to the industry-specific US frontier. Calculations are based on data for all 1,235 industry-year cells in the estimation sample for productivity growth models.

Source: Authors' calculations using ONS and other data. All statistical results remain Crown Copyright.

\section{Table B.4: Descriptive statistics}

\begin{tabular}{|c|c|c|c|}
\hline Variable & Mean & Median & $\begin{array}{l}\text { Standard } \\
\text { Deviation }\end{array}$ \\
\hline \multicolumn{4}{|l|}{ ARD establishment sample } \\
\hline growth of total factor productivity $_{\text {it }}$ & -0.008 & -0.005 & 0.113 \\
\hline growth of total factor productivity ${ }_{i t}$, mark-up corrected & -0.001 & 0.009 & 0.165 \\
\hline growth of labor productivity $_{\text {it }}$ & 0.011 & 0.011 & 0.136 \\
\hline foreign firm entry rate $_{\mathrm{jt}-1}$ & 0.001 & 0 & 0.005 \\
\hline number of employees in new foreign firms $/ 1000_{\mathrm{jt}-1}$ & 0.054 & 0 & 0.234 \\
\hline number of employees $/ 1000_{\mathrm{jt}-1}$ & 40.326 & 30.773 & 32.035 \\
\hline 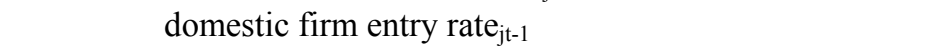 & 0.025 & 0.020 & 0.020 \\
\hline import penetration $_{\mathrm{jt}-1}$ & 0.967 & 0.932 & 0.472 \\
\hline competition $_{\mathrm{jt}-1}$ & 0.899 & 0.909 & 0.062 \\
\hline distance to the frontier ${ }_{\mathrm{jt}-1}$, labor productivity-based & 0.209 & 0.203 & 0.279 \\
\hline distance to the frontier ${ }_{\mathrm{jt}-1}$, TFP-based & 0.091 & 0.105 & 0.138 \\
\hline US capital-labor ratio (real, in million $£$ ) & 36.127 & 28.412 & 31.891 \\
\hline US skilled real wage in $1000 £$ & 19.233 & 19.020 & 3.460 \\
\hline
\end{tabular}

\section{LSE firm sample}

number of US-patents it $_{\text {it }}$

8.129

0

24.100

foreign firm entry rate $_{\mathrm{jt}-1}$

0.002

0.0002

0.004

number of employees in new foreign firms $/ 1000_{\mathrm{jt}-1}$

0.157

0.021

0.375

number of employees $/ 1000_{\mathrm{jt}-1}$

91.722

56.163

76.106

domestic firm entry rate jt-1 $_{\mathrm{j}-1}$

0.022

0.019

0.015

import penetration $\mathrm{j}_{\mathrm{j}-1}$

1.029

1.088

0.467

competition $_{\mathrm{jt}-1}$

0.892

0.903

0.056

distance to the frontier ${ }_{\mathrm{jt}-1}$, labor productivity-based

0.208

0.230

0.279

distance to the frontier ${ }_{\mathrm{jt}-1}$, tfp-based

0.082

0.107

0.148

-sample

24.326

1.532

80.743

0.668

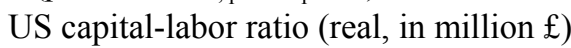

39.233

0.089

0.471

US R\&D intensity

0.326

29.299

32.933

US skilled worker share

0.094

0.082

0.134

Notes: The ARD establishment sample includes 23,802 observations on 4,947 domestic incumbent establishments between 1987 and 1993. The LSE firm sample includes 1,085 observations on 176 firms listed at the London stock exchange between 1987 and 1993. Industry variables are measured at the 4-digit (3-digit) industry level in the ARD establishment (LSE firm) sample except for import penetration and US R\&D intensity that are at the 2-digit level.

Source: Authors' calculations using ONS and other data. All statistical results remain Crown Copyright. 